\title{
In pursuit of a better broiler: carcass traits and muscle myopathies in conventional and slower-growing strains of broiler chickens
}

\author{
Midian N. Santos, ${ }^{*}$, Daniel Rothschild, ${ }^{*}, \dagger$ Tina M. Widowski, ${ }^{*}, \dagger$ Shai Barbut,${ }^{\dagger}$ Elijah G. Kiarie, ${ }^{*}$ \\ Ira Mandell, ${ }^{*}$ Michele T. Guerin, ${ }^{\S}{ }^{\dagger}$ A. Michelle Edwards, ${ }^{*}$ and Stephanie Torrey ${ }^{*, \dagger, 1}$ \\ *Department of Animal Biosciences, Ontario Agricultural College, University of Guelph, Guelph, ON N1G 2W1, \\ Canada ${ }^{\dagger}$ Campbell Centre for the Study of Animal Welfare, University of Guelph, Guelph, ON N1G 2W1, Canada; \\ ${ }^{\ddagger}$ Department of Food Science, Ontario Agricultural College, University of Guelph, Guelph, ON N1G 2W1, Canada; \\ ${ }^{\S}$ Department of Population Medicine, Ontario Veterinary College, University of Guelph, Guelph, ON N1G 2W1, \\ Canada; and "Ontario Agricultural College, University of Guelph, Guelph, ON N1G 2W1, Canada
}

\begin{abstract}
Selection for accelerated growth rate and high breast yield in broiler chickens have been associated with an increase in myopathies, including wooden breast (WB) and white striping (WS). To investigate effects of growth rate on carcass traits and incidence of myopathies, 14 strains were evaluated, encompassing 2 conventional $\left(\mathbf{C O N V}\right.$; strains B and C: $\mathrm{ADG}_{0-48}>60 \mathrm{~g} / \mathrm{d}$ ) and 12 slower-growing (SL) strains. The latter were categorized based on growth rate: FAST (strains F, G, I and $\mathrm{M} ; \mathrm{ADG}_{0-62}=53-55 \mathrm{~g} / \mathrm{d}$ ), MOD (strains E, H, O and $\mathrm{S} ; \mathrm{ADG}_{0-62}=50-51 \mathrm{~g} / \mathrm{d}$ ), and SLOW (strains D, J, K and $\mathrm{N} ; \mathrm{ADG}_{0-62}<50 \mathrm{~g} / \mathrm{d}$ ). In a randomized incomplete block design, 7,216 mixed-sex birds were equally allocated into 164 pens (44 birds/pen; $30 \mathrm{~kg} / \mathrm{m}^{2}$ ), with each strain represented in 8 to 12 pens over 2 to 3 production cycles. From each pen, 4 males and 4 females were processed at 2 Target Weights (TWs) based on their expected time to reach $2.1 \mathrm{~kg}$ BW (TW 1: $34 \mathrm{~d}$ for
\end{abstract}

CONV; $48 \mathrm{~d}$ for SL strains) and $3.2 \mathrm{~kg} \mathrm{BW}$ (TW 2: $48 \mathrm{~d}$ for CONV; $62 \mathrm{~d}$ for SL strains). Weights and yields for the carcass, breast, drumsticks, thighs, and wings were obtained; breast fillets were assessed to determine the presence and severity of WB and WS. At both TWs, breast yield was higher as growth rate increased $(P<0.001)$, with CONV having greater breast yield than other categories. Strain $F$ had the greatest breast yield at both TWs $(P<0.001)$ within the FAST category. At TW 2, CONV had the greatest incidence of WB and WS $(P<0.001)$. However, within FAST, strain $\mathrm{F}$ had the greatest incidence of myopathies $(P<0.001)$ at both TWs, exhibiting values as high or as greater than CONV birds. The incidence of WB and WS in strains with differing growth rates but high breast meat yield suggests that the latter may play a major role in the occurrence of these myopathies.

Key words: chicken meat, meat yield, myopathies, processing traits, slow-growth

$$
\begin{array}{r}
2021 \text { Poultry Science 100:101309 } \\
\text { https://doi.org/10.1016/j.psj.2021.101309 }
\end{array}
$$

\section{INTRODUCTION}

There has been a significant increase in preference for chicken meat globally, with world per capita consumption rising over $250 \%$ over the past $50 \mathrm{yr}$ (FAO, 2019). Chicken is now the most consumed meat in North America and the second most consumed meat worldwide after pork (FAO, 2019). The increase in demand for chicken meat is mainly due to its high nutrient content, lack of religious or cultural restrictions, affordability, convenience, and simple

(C) 2021 The Authors. Published by Elsevier Inc. on behalf of Poultry Science Association Inc. This is an open access article under the CC BY-NC-ND license (http://creativecommons.org/licenses/by-nc-nd/ $4.0 /)$.

Received February 5, 2021

Accepted June 1, 2021.

${ }^{1}$ Corresponding author: storrey@uoguelph.ca preparation for a variety of individual cut-up portions (Barbut, 2015; Wideman, 2016; Petracci et al., 2019). To meet the growing demand, selection criteria have been adopted to focus on strains with fast, early growth, and accelerated muscle accretion (Petracci et al., 2015). These strains selected for rapid growth, commonly referred to as conventional or fast-growing strains, can reach over $2 \mathrm{~kg}$ body weight in about $35 \mathrm{~d}$, whereas unselected strains from the 1940s require over $100 \mathrm{~d}$ to reach the same target weight (Siegel et al., 2009). This represents an increase of over $300 \%$ in the growth rate of broiler chickens in the past 60 yr (Knowles et al., 2008), with genetic selection being considered the major contributor to this improvement (Havenstein et al., 2003a). Besides differences in growth and body weight, genetic selection has also been associated with changes in body composition and processing traits, with conventional broiler strains having greater 
carcass and breast yields in comparison to unselected strains (Havenstein et al., 2003a).

Selection for high breast yield can be attributed to the increased demand for further processed products and cutup portions rather than the whole carcass and to the increase in preference for breast meat in Western markets (Petracci et al., 2015). Because breast meat is one of the most valuable cuts of the carcass, strategies to improve the quality and appearance of the breast are relevant to primary breeding companies and producers to avoid economic losses associated with condemnations and rejections (Cruz et al., 2017). However, the increase in growth rate and breast yield in fast-growing strains has been accompanied with muscle disorders including wooden breast and white striping, which are 2 major myopathies reported for conventional strains of broiler chickens (Kuttappan et al., 2012c; Petracci et al., 2019). These disorders have posed a growing concern to producers and retailers due to their high incidence and significant economic impacts to the poultry industry (Kuttappan et al., 2012c; Cai et al., 2018; Petracci et al., 2019).

Wooden breast (WB), also referred to as woody breast, was first described by Sihvo et al. (2014) and is characterized by a distinct hardness that can affect different regions of the Pectoralis major (Cai et al., 2018). Affected breasts can also exhibit bulging and pale areas that can be associated with the presence of exudate and hemorrhage in severely affected fillets (Barbut, 2019). Wooden breast can be classified as mild, moderate or severe and different degrees of this myopathy have been reported in many countries where fast-growing broiler chickens are raised (Kuttappan et al., 2012a; Sihvo et al., 2014; Cruz et al., 2017; Ferreira et al., 2020). Recent industry reports have suggested that about $20 \%$ of the breast fillets are affected by WB, although a wide range of incidence has been reported in different flocks and studies (as reviewed by Barbut, 2019 and Petracci et al., 2019).

White striping (WS) was first described in 2009 and is characterized by white striations parallel to the muscle fibers in breast fillets (Kuttappan et al., 2009). Similar to WB, WS is classified according to the severity of the lesions, which can vary from mild to severe (Kuttappan et al., 2012c). Microscopic analyses suggested that the white striations are a result of fat and connective tissue infiltration in the muscle (Kuttappan et al., 2013a). Recent studies have shown that the incidence of different degrees of WS in modern strains of broiler chickens can surpass 90\% (Kuttappan et al., 2017; Petracci et al., 2019; Che et al., 2020).

The effects of WB and WS on meat quality, nutritional value, and technological properties of raw and cooked meat have been well documented (Trocino et al., 2015; Mudalal et al., 2015; Soglia et al., 2016; Dalgaard et al., 2018). In addition, severe WB and WS breast fillets may require sorting at processing plants, due to the negative impacts of these meat abnormalities on consumer acceptance, and meat processing (Kuttappan et al., 2012b; Petracci et al., 2019). The economic losses caused by these meat defects have been estimated to cost over $\$ 1$ billion per year in the USA alone (Barbut, 2019).
In addition to their impact on meat quality, muscle myopathies are linked to degeneration and regeneration of muscle fibers, necrosis, hypoxia, and infiltration of inflammatory cells (Petracci et al., 2019; Hosotani et al., 2020). Furthermore, recent findings suggest these muscle disorders may alter bird behavior and have potential welfare implications for broiler chickens (Kawasaki et al., 2016; Norring et al., 2018). In this context, strategies to mitigate the incidence of these myopathies have been studied. Some of these interventions include modulation of growth (Kuttappan et al., 2012a; Gratta et al., 2019), dietary alterations (Kuttappan et al., 2012b; Cruz et al., 2017), manipulation of incubation temperature and embryonic development (Clark et al., 2017), reduced age at slaughter (Kuttappan et al., 2017), and reduction of breast yield through genetic selection or nutrition (Bailey et al., 2015; Alnahhas et al., 2016; Cruz et al., 2017; Bailey et al., 2020). Because these strategies have demonstrated limited or no effects on the incidence of WB and WS, the use of slower-growing strains has been suggested as an alternative to alleviate these disorders (Petracci et al., 2019). However, there is little information comparing the incidence of muscle myopathies in slower-growing and conventional broiler chickens raised under similar conditions.

Thus, in this study, we aimed to investigate the differences in carcass traits and the incidence of myopathies among 14 strains of broiler chickens (2 conventional and 12 slower-growing) raised indoors under similar conditions. We hypothesized that slower-growing strains of broiler chickens would have different meat yields and lower incidence of myopathies compared to conventional strains.

\section{MATERIALS AND METHODS}

\section{Hatching, Housing, and Rearing}

All procedures in this study were reviewed and approved by the University of Guelph's Animal Care Committee (AUP\#3746) and followed the Canadian Council for Animal Care's guidelines (CCAC, 2009) . This paper is part of a large multidisciplinary study that encompassed measurement of different variables to assess productivity, behavior, meat quality, and welfare of conventional and slower-growing strains of broiler chickens. The detailed description of the incubation conditions, animals, housing, and husbandry was reported by Torrey et al. (2021).

Briefly, a total of 8 trials were conducted at the Arkell Poultry Research Station (Guelph, ON, Canada), with each trial representing a typical production cycle for broiler chickens, from incubation to slaughter. Fertile eggs from 14 strains (2 conventional and 12 slower-growing) obtained from breeding companies located in North America were incubated and hatched in one federally inspected facility under similar conditions. All the birds were reared in a single room with 28 floor pens (160 $\mathrm{cm} \times 238 \mathrm{~cm}$; width $\times$ length) divided into 4 blocks based on location, to account for microclimate differences at pen level. The birds from each strain were raised 
under similar conditions in up to 3 trials, with 4 pens per trial, located in each block of the room, totalizing 12 pens per strain. Due to the availability of fertile eggs and project logistics, strain $\mathrm{M}$ was only tested in 2 trials totaling 8 pens. Again, details about the methodology and strains tested in each trial are described elsewhere (Torrey et al., 2021). Chicks were vent sexed at hatch, and each strain had equal numbers of males and females, with each pen containing 44 birds (22 males and 22 females). The group weight for each pen was obtained prior to placement and 12 birds (6 males, 6 females) per pen were wing tagged, individually weighed, and painted with livestock paint to differentiate males and females. These birds were used as focal birds for behavioral, physiological, bone quality, and meat quality assessments described in other studies not yet published. All the birds were vaccinated against Marek's disease, coccidiosis, and infectious bronchitis (Torrey et al., 2021).

Over the 8 trials, 164 pens were used. Each pen contained a round feeder (diameter: $33.75 \mathrm{~cm}$ ) and 5 nipple drinkers. The pens were enriched with the following items: a platform raised $30 \mathrm{~cm}$ above the litter attached to a $25^{\circ}$ ramp, a mineral PECKstone (Protekta, Inc., Lucknow, Ontario, Canada), a hanging round scale (diameter: 50.8 $\mathrm{cm}$ ), and hanging nylon ropes containing polyester strips. Soft wood shavings were used as bedding material and replaced in every trial. Pens were separated by solid white plastic walls to prevent visual contact between birds located in different pens. Lighting schedule was maintained at $23 \mathrm{~h}$ of light (L): $1 \mathrm{~h}$ on the dark (D) from d 1 to $\mathrm{d} 3$. From d 4 onward, a photoperiod of 16L:8D was provided, with lights turned on at 06:00 $\mathrm{h}$ and turned off at 22:00 $\mathrm{h}$. The light intensity was kept at 20 lux throughout the trials. Room temperature was $32^{\circ} \mathrm{C}$ at placement and gradually decreased to $21^{\circ} \mathrm{C}$ at 5 wk of age. The birds had ad libitum access to an all-vegetable, antibiotic-free diet, formulated based on nutrient requirements for a slower-growing broiler (Torrey et al., 2021). The diet was provided in 3 phases (starter, grower, and finisher); diet was transitioned when slower-growing strains reached a similar feed intake to conventional birds. Starter, grower, and finisher diet were prepared as fine crumble, coarse crumble, and short pellet, respectively.

Due to the effects of body weight $(\mathbf{B W})$ on the variables evaluated in our study, conventional and slowergrowing strains were processed at 2 target weights (TWs) based on the breeder estimated age to reach $2.1 \mathrm{~kg}$ liveweight ( $\mathbf{T W} \mathbf{1}$ ) and $3.2 \mathrm{~kg}$ liveweight (TW 2). At TW 1, conventional and slower-growing strains were 34 and $48 \mathrm{~d}$ of age, respectively. At TW 2, conventional and slower-growing strains were 48 and $62 \mathrm{~d}$ of age, respectively. On d 34 and 48, the group size for the pens not processed was reduced to maintain a commercial stocking density of $30 \mathrm{~kg} / \mathrm{m}^{2}$.

\section{Processing Measurements}

On the day before processing, 8 focal birds ( 4 females and 4 males) per pen from those to be processed were individually weighed and labeled with a colored zip tie on one of their legs. These labeled birds were part of the 12 wing-tagged focal birds and represented approximately $18 \%$ of the initial pen population (prior removal of birds to keep stocking density of $30 \mathrm{~kg} / \mathrm{m}^{2}$ ) to encompass a representative sample size, while considering the logistics of the project (e.g., transportation, capacity of the processing plant, and labor). The colored labels enabled the identification of each pen and differentiation of selected birds from the remaining birds being processed. The group weight was obtained to determine the final BW for each pen processed. The feeders were removed from each pen at 23:00 $\mathrm{h}$ the night prior to processing. Birds had free access to water until loading. The next morning at 06:00 $\mathrm{h}$, the birds were placed into crates and transported $35 \mathrm{~min}$ to a provincially inspected processing plant. Birds were hung on a shackle line and electrically stunned in a brine-water bath $(25 \mathrm{~V}$ and $120 \mathrm{~Hz}$ for $10 \mathrm{~s}$ ), and then bled for $90 \mathrm{~s}$. Following mechanical defeathering and manual evisceration, the carcasses were air-chilled at $4^{\circ} \mathrm{C}$ for $5 \mathrm{~h}$ and transported in coolers, to the university, where the carcasses were kept overnight at $4^{\circ} \mathrm{C}$. Ready-to-cook carcass weight (after removal of the viscera, feet, and head) was obtained and carcass yield was expressed as the percentage of the live weight $(\mathbf{L W})$ obtained the day before processing. Trained butchers manually deboned the carcasses and weights for the skinless and boneless breast muscle (Pectoralis major and Pectoralis minor), wings, drumsticks, and thighs were obtained. The yields of the carcass portions are reported as the percentage of the ready-to-cook carcass weight and of the LW.

During processing, some of the samples were over scalded. Because the birds were processed in a commercial processing plant, it is unclear why overscalding occurred more often in some trials and processing than others, as no pattern was observed regarding season, strains, BW, and age of birds showing overscalded breasts. Color of the skinless breast fillets was measured at 3 different locations (cranial, medial and caudal) using Minolta CR-400 with Spectra QC-400 software (Folio Instruments, Kitchener, ON, Canada) to identify possibly overscalded samples, following the CIE $\mathrm{L}^{*} \mathrm{a}^{*} \mathrm{~b}^{*}$ system, in which $\mathrm{L}^{*}$ represents lightness, $a^{*}$ represents redness, and $b^{*}$ represents yellowness. Samples showing $L^{*}$ values equal or greater than 59 were removed from the WS assessment (Sirri et al., 2011; da Silva-Buzanello et al., 2019).

This value was used as a cut-off point to be conservative in our analysis, resulting in the exclusion of light breast samples potentially due to overscalding that could interfere the assessment of WS.

\section{Assessment of Wooden Breast and White Striping Myopathies}

Following deboning, the presence and severity of WB and WS were assessed. To keep the evaluation consistent, the breast fillets were evaluated by a single trained 
researcher throughout all the trials. The researcher was trained in palpation for $\mathrm{WB}$ and visual assessment of WS (described below) by a field expert from a breeding company. In addition, each breast sample in each trial was evaluated twice at random to ensure consistency in the scoring scheme adopted and good intraobserver reliability. The values were compared using PROC FREQ in SAS version 9.4 (SAS Institute Inc., Cary, NC), with the "agree" option included to calculate weighted kappa statistics. For WB and WS, weighted kappa statistics $\left(\mathrm{K}_{\mathrm{w}}\right)$ were 0.811 and 0.845 , respectively, indicating almost perfect Kappa agreement $\left(\mathrm{K}_{\mathrm{w}}>0.80\right)$ for both variables. The breast fillets were palpated and scored for WB levels, using a 4-point scale modified from Cruz et al. (2017) and classified as: 0 (normal) - no hardness or paleness detected on the surface of the breast fillet; 1 (moderate light) - hardness detected in up to one third of the breast fillet, present in cranial and/or caudal regions; 2 (moderate severe)- hardness affecting up to two-thirds of the breast fillet; and 3 (severe) hardness detected throughout the fillet, commonly associated with presence of hemorrhage and exudate on the surface of the fillet. Similarly, breast fillets were visually examined and scored for WS using the 4-point classification scheme previously described by Kuttappan et al. (2016), in which 0 (normal) represents breast fillets with no visible white lines; 1 (moderate) represents breast fillets showing thin white lines ( $<1 \mathrm{~mm}$ thick); 2 (severe) represents breast fillets exhibiting large and noticeable white lines (1-2 mm thick); and 3 (extreme) includes breasts fillets presenting thick white lines $(>2 \mathrm{~mm})$ that commonly merge with other lines and cover a major surface of the breast fillet.

Due to the low proportion of the severe score (3) for WB and WS, scores 2 and 3 were combined and classified as moderate-severe which represents more evident muscle defects that may result in rejection or condemnation. The total incidence of breast fillets exhibiting WB or WS and moderate-severe scores of WB or WS were calculated and reported as a percentage of total breasts examined. Average severity index was obtained separately for WB and WS using the following calculation for each strain: $((\mathrm{n} 0 \times 0)+(\mathrm{n} 1 \times 1)+(\mathrm{n} 2 \times 2)+(\mathrm{n} 3 \times 3)) /$ $(\mathrm{n} 0+\mathrm{n} 1+\mathrm{n} 2+\mathrm{n} 3))$, where $\mathrm{n}$ represents the number of breast fillets in each score. The average mean myopathy score of WB and WS for each strain could range from 0 (all fillets receiving scores of 0 ) to 3 (all fillets receiving scores of 3). Therefore, greater values are associated with greater severity of myopathies.

\section{Statistical Analyses}

To simplify the analysis of differences related to growth rate, the strains were grouped into 4 categories based on their average daily gain (ADG) to TW 2 (48 and $62 \mathrm{~d}$ for conventional and slower-growing strains, respectively): Conventional (CONV; strains $\mathrm{B}$ and $\mathrm{C}$; $\mathrm{ADG}_{0-48}=66.0$ to $\left.68.7 \mathrm{~g} / \mathrm{d}\right)$; fastest slower-growing (FAST; strains F, G, I, and M; $\mathrm{ADG}_{0-62}=53.5$ to 55.5 g/d); moderate slower-growing (MOD; strains E, H, O, and $\mathrm{S} ; \mathrm{ADG}_{0-62}=50.2$ to $51.2 \mathrm{~g} / \mathrm{d}$ ); and slowest slowergrowing (SLOW; strains $\mathrm{D}, \mathrm{J}, \mathrm{K}$, and $\mathrm{N} ; \mathrm{ADG}_{0-62}=43.6$ to $47.7 \mathrm{~g} / \mathrm{d})$.

Data were analyzed as an incomplete block design, with pen as the experimental unit, using Generalized linear mixed models (GLIMMIX) in SAS, version 9.4 (SAS Institute Inc.). Category, strain nested within category, sex, target weight and the interactions were included as fixed effects to compare the variables tested at a similar BW. Trial and block nested within trial were included as random effects. Contrast statements were used to test the differences among categories and strains within categories. Pairwise comparisons were corrected using Tukey adjustment to explore multiple comparisons and differences between categories, strains, and sex. Differences between sex and the interactions of sex with category or strain (within category) are not provided in data tables but are described in the results section with respective $P$-values if significant. Assumptions of the models were checked by analyzing the residuals to check for normality using quantile-quantile plots and Shapiro-Wilk test. Linearity and homogeneity were assessed using boxplots and studentized residuals. The Gaussian distribution was used for those variables that met all the model assumptions. For carcass traits (absolute and relative values), lognormal distribution was required to meet the model assumptions. The relationships between the incidence of breasts affected by myopathies (WB or WS) and the carcass traits for each strain category were investigated using Spearman's rank correlation coefficients. Correlation coefficients were classified as weak $\left(\mathrm{r}_{\mathrm{s}}\right.$ $<|0.35|)$, moderate $\left(\mathrm{r}_{\mathrm{s}}|0.35| \leq \mathrm{r}_{\mathrm{s}}<|0.67|\right)$, or strong $\left(\mathrm{r}_{\mathrm{s}}\right.$ $\geq|0.68|$ ) (Bohrer et al., 2018). For all tests performed, statistical significance was considered at $P<0.05$.

\section{RESULTS}

The differences in variables measured in this study are described as comparisons between categories (CONV, FAST, MOD, and SLOW) and comparisons of strains within categories at both TWs. Significant interactions between category and sex or strain (within category) and sex are described in the results below for each variable evaluated. As expected, category affected all the variables evaluated. However, some variables differed within category, suggesting distinct criteria in strains selected for similar growth rate. Differences in processing traits between categories are presented in Table 1 and differences among strains (within category) are presented in Tables 2-5. The incidence, severity and average scores of WB and WS are presented in Figures 1-6. The incidence of each score (0 to 3 ) of WB and WS by category is provided in Figure 7 (descriptive statistics).

\section{Processing Traits}

Live Weight. Category affected LW $(P<0.001)$ at both TWs (Table 1). However, an interaction between 
Table 1. Effect of category on live weight (LW), carcass weight (CW), and cut-up yields of broiler chickens (LS-means \pm SEM) at Target Weights 1 and 2 .

\begin{tabular}{|c|c|c|c|c|}
\hline \multirow{2}{*}{$\begin{array}{l}\text { Variable } \\
\text { Target weight } \mathbf{1}^{1}\end{array}$} & \multicolumn{4}{|c|}{ Category } \\
\hline & CONV & FAST & MOD & SLOW \\
\hline Live wt (g) & $1,881 \pm 36.9^{\mathrm{c}}$ & $2,431 \pm 31.0^{\mathrm{a}}$ & $2,348 \pm 28.3^{\mathrm{a}}$ & $2,001 \pm 24.1^{\mathrm{b}}$ \\
\hline Carcass wt (g) & $1,327 \pm 27.9^{\mathrm{b}}$ & $1,736 \pm 24.0^{\mathrm{a}}$ & $1,661 \pm 21.4^{\mathrm{a}}$ & $1,373 \pm 17.8^{\mathrm{b}}$ \\
\hline Breast wt (g) & $400.6 \pm 11.08^{\mathrm{c}}$ & $483.9 \pm 8.72^{\mathrm{a}}$ & $443.3 \pm 7.53^{\mathrm{b}}$ & $330.3 \pm 5.62^{\mathrm{d}}$ \\
\hline Thigh wt (g) & $202.9 \pm 4.52^{\mathrm{c}}$ & $273.4 \pm 3.99^{\mathrm{a}}$ & $266.1 \pm 3.64^{\mathrm{a}}$ & $226.9 \pm 3.11^{\mathrm{b}}$ \\
\hline Drumstick wt (g) & $171.3 \pm 2.93^{\mathrm{c}}$ & $231.2 \pm 2.58^{\mathrm{a}}$ & $224.7 \pm 2.36^{\mathrm{a}}$ & $192.5 \pm 2.02^{\mathrm{b}}$ \\
\hline Wing wt (g) & $134.8 \pm 2.66^{\mathrm{c}}$ & $183.3 \pm 2.36^{\mathrm{a}}$ & $182.5 \pm 2.21^{\mathrm{a}}$ & $158.0 \pm 1.91^{\mathrm{b}}$ \\
\hline Carcass yield $(\% \mathrm{LW})^{2}$ & $70.6 \pm 0.42^{\mathrm{a}}$ & $71.4 \pm 0.28^{\mathrm{a}}$ & $70.8 \pm 0.26^{\mathrm{a}}$ & $68.7 \pm 0.26^{\mathrm{b}}$ \\
\hline Breast yield (\% CW $)^{3}$ & $30.2 \pm 0.35^{\mathrm{a}}$ & $27.9 \pm 0.22^{\mathrm{b}}$ & $26.7 \pm 0.19^{\mathrm{c}}$ & $24.0 \pm 0.18^{\mathrm{d}}$ \\
\hline Breast yield (\% LW) & $21.3 \pm 0.28^{\mathrm{a}}$ & $19.9 \pm 0.17^{\mathrm{b}}$ & $18.9 \pm 0.16^{\mathrm{c}}$ & $16.5 \pm 0.14^{\mathrm{d}}$ \\
\hline Thigh yield (\% CW) & $15.3 \pm 0.27^{\mathrm{b}}$ & $15.8 \pm 0.18^{\mathrm{b}}$ & $16.0 \pm 0.17^{\mathrm{ab}}$ & $16.5 \pm 0.18^{\mathrm{a}}$ \\
\hline Thigh yield (\% LW) & $10.8 \pm 0.19$ & $11.2 \pm 0.13$ & $11.3 \pm 0.12$ & $11.4 \pm 0.12$ \\
\hline Drumstick yield (\% CW) & $12.9 \pm 0.14^{\mathrm{c}}$ & $13.3 \pm 0.10^{\mathrm{bc}}$ & $13.5 \pm 0.09^{\mathrm{b}}$ & $14.0 \pm 0.09^{\mathrm{a}}$ \\
\hline Drumstick yield (\% LW) & $9.1 \pm 0.09^{\mathrm{b}}$ & $9.5 \pm 0.07^{\mathrm{a}}$ & $9.6 \pm 0.06^{\mathrm{a}}$ & $9.6 \pm 0.06^{\mathrm{a}}$ \\
\hline Wing yield (\% CW) & $10.1 \pm 0.13^{\mathrm{c}}$ & $10.6 \pm 0.09^{\mathrm{c}}$ & $11.0 \pm 0.09^{\mathrm{b}}$ & $11.5 \pm 0.09^{\mathrm{a}}$ \\
\hline Wing yield (\% LW) & $7.2 \pm 0.09^{\mathrm{c}}$ & $7.5 \pm 0.06^{\mathrm{b}}$ & $7.8 \pm 0.06^{\mathrm{a}}$ & $7.9 \pm 0.06^{\mathrm{a}}$ \\
\hline
\end{tabular}

\section{Target weight $2^{4}$}

\begin{tabular}{|c|c|c|c|c|}
\hline Live wt $(\mathrm{g})$ & $3,285 \pm 58.8^{\mathrm{ab}}$ & $3,417 \pm 42.1^{\mathrm{a}}$ & $3,182 \pm 36.4^{\mathrm{b}}$ & $2,809 \pm 32.0^{\mathrm{c}}$ \\
\hline Carcass wt (g) & $2,415 \pm 46.4^{\mathrm{ab}}$ & $2,495 \pm 33.1^{\mathrm{a}}$ & $2,314 \pm 28.4^{\mathrm{b}}$ & $1,994 \pm 24.4^{\mathrm{c}}$ \\
\hline Breast wt (g) & $814.6 \pm 20.58^{\mathrm{a}}$ & $733.2 \pm 12.78^{\mathrm{b}}$ & $642.4 \pm 10.37^{\mathrm{c}}$ & $503.8 \pm 8.11^{\mathrm{d}}$ \\
\hline Thigh wt (g) & $351.2 \pm 7.14^{\mathrm{b}}$ & $384.7 \pm 5.48^{\mathrm{a}}$ & $366.1 \pm 4.78^{\mathrm{ab}}$ & $325.2 \pm 4.23^{\mathrm{c}}$ \\
\hline Drumstick wt (g) & $301.3 \pm 4.70^{\mathrm{b}}$ & $322.7 \pm 3.52^{\mathrm{a}}$ & $306.7 \pm 3.08^{\mathrm{b}}$ & $270.9 \pm 2.71^{\mathrm{c}}$ \\
\hline Wing wt $(\mathrm{g})$ & $226.6 \pm 4.07^{\mathrm{bc}}$ & $249.0 \pm 3.11^{\mathrm{a}}$ & $238.9 \pm 2.75^{\mathrm{ab}}$ & $217.6 \pm 2.50^{\mathrm{c}}$ \\
\hline Carcass yield (\% LW) & $73.5 \pm 0.39^{\mathrm{a}}$ & $73.1 \pm 0.28^{\mathrm{a}}$ & $72.7 \pm 0.26^{\mathrm{a}}$ & $71.0 \pm 0.26^{\mathrm{b}}$ \\
\hline Breast yield $(\% \mathrm{CW})$ & $33.7 \pm 0.37^{\mathrm{a}}$ & $29.4 \pm 0.21^{\mathrm{b}}$ & $27.8 \pm 0.19^{\mathrm{c}}$ & $25.3 \pm 0.17^{\mathrm{d}}$ \\
\hline Breast yield (\% LW) & $24.8 \pm 0.30^{\mathrm{a}}$ & $21.4 \pm 0.18^{\mathrm{b}}$ & $20.2 \pm 0.16^{\mathrm{c}}$ & $17.9 \pm 0.141^{\mathrm{d}}$ \\
\hline Thigh yield $(\% \mathrm{CW})$ & $14.5 \pm 0.24^{\mathrm{c}}$ & $15.4 \pm 0.17^{\mathrm{b}}$ & $15.8 \pm 0.16^{\mathrm{ab}}$ & $16.3 \pm 0.17^{\mathrm{a}}$ \\
\hline Thigh yield (\% LW) & $10.7 \pm 0.17^{\mathrm{b}}$ & $11.2 \pm 0.12^{\mathrm{a}}$ & $11.5 \pm 0.11^{\mathrm{a}}$ & $11.6 \pm 0.12^{\mathrm{a}}$ \\
\hline Drumstick yield (\% CW) & $12.5 \pm 0.13^{\mathrm{d}}$ & $12.9 \pm 0.09^{\mathrm{c}}$ & $13.3 \pm 0.08^{\mathrm{b}}$ & $13.6 \pm 0.09^{\mathrm{a}}$ \\
\hline Drumstick yield (\% LW) & $9.2 \pm 0.09^{\mathrm{c}}$ & $9.4 \pm 0.06^{\mathrm{bc}}$ & $9.6 \pm 0.06^{\mathrm{ab}}$ & $9.7 \pm 0.02^{\mathrm{a}}$ \\
\hline Wing yield (\% CW) & $9.4 \pm 0.11^{\mathrm{d}}$ & $9.9 \pm 0.08^{\mathrm{c}}$ & $10.3 \pm 0.08^{\mathrm{b}}$ & $10.9 \pm 0.08^{\mathrm{a}}$ \\
\hline Wing yield (\% LW) & $6.9 \pm 0.08^{\mathrm{d}}$ & $7.3 \pm 0.06^{\mathrm{c}}$ & $7.5 \pm 0.06^{\mathrm{b}}$ & $7.7 \pm 0.06^{\mathrm{a}}$ \\
\hline
\end{tabular}

At Target Weight 1, CONV and other categories were 34 and $48 \mathrm{~d}$ of age, respectively. At Target Weight 2, CONV and other categories were 48 and 62 d, respectively.

${ }^{\text {a-d }}$ Different superscripts within the same row represent differences among categories $(P<0.05)$.

${ }^{1}$ Number of birds per category at target weight 1 : CONV: $\mathrm{n}=64$; FAST: $\mathrm{n}=155 ;$ MOD: $\mathrm{n}=174 ;$ SLOW: $\mathrm{n}=173$

${ }^{2}$ Yields calculated relative to live weight obtained $1 \mathrm{~d}$ before processing.

${ }^{3}$ Yields calculated as a ratio to the eviscerated carcass weight.

${ }^{4}$ Number of birds per category at target weight 2: CONV: $\mathrm{n}=80$; FAST: $\mathrm{n}=161$;OD: $\mathrm{n}=186 ;$ SLOW: $\mathrm{n}=187$.

target weight and category $(P<0.001$; Table 1$)$ was found, demonstrating that BW at each target weight depended on category. At TW 1, FAST and MOD categories were heavier than CONV and SLOW, and SLOW was heavier than CONV. At TW 2, SLOW was lighter than the other categories and MOD was lighter than FAST, while CONV was similar to FAST and MOD. Males were heavier than females across all the categories $(P<0.001)$.

Overall, there were no differences in LW between strains within the same category (Tables 2, 3 and 5), except among MOD birds, where strain E was $300 \mathrm{~g}$ heavier than strain $\mathrm{S}$ (Table $4 ; P=0.007$ ) at TW 1 . However, at TW 2, this difference disappeared. The absolute weights for each category in both target weights are presented in Table 1 and differences between strains within category are presented in Tables 2-5.

Carcass Yield. At both TWs, SLOW had the lowest carcass yield $(P<0.001$; Table 1$)$, with no difference in carcass yield among the other categories. There was no interaction between target weight and category $(P=0.319)$ on carcass yield. Overall, males had greater carcass yields than females $(71.8 \pm 0.15 \%$ vs. $71.2 \pm$ $0.15 \% ; P=0.005)$. No interactions between category and sex $(P=0.790)$ or category and strain $(P=0.161)$ were found. Carcass yields differed $(P<0.05)$ among FAST (Table 3) and SLOW (Table 5) strains with an interaction between strain within category and target weight present $(P=0.018)$. Within FAST strains (Table 3), strain $\mathrm{F}$ had greater carcass yields than strains $\mathrm{G}$ and $\mathrm{M}$ at TW 1, with strain I being similar to the other FAST strains (Table 3). At TW 2, strain F had greater carcass yield than the other FAST strains. Among SLOW strains (Table 5), strain D had lower carcass yield than strains $\mathrm{J}$ and $\mathrm{K}$ at TW 1 , whereas at TW 2 , carcass yield for strain $\mathrm{D}$ was similar to strain $\mathrm{K}$, but lower than strains $\mathrm{J}$ and $\mathrm{N}$.

Breast Yield. Breast yield was impacted by category, strain, target weight and sex $(P<0.001)$. Among categories, a significantly higher breast yield was observed as the growth rate increased, with $\mathrm{CONV}>\mathrm{FAST}>$ MOD > SLOW, which was consistent at both TWs, despite the differences in age, LW and carcass weight (Table 1). While females had greater breast yields 
Table 2. Mean values (LS-means \pm SEM) for live weight (LW), carcass weight $(\mathrm{CW})$, and cut-up yields among CONV strains of broiler chickens at Target Weights 1 and 2 .

\begin{tabular}{lcc}
\hline \hline & \multicolumn{2}{c}{ Strain } \\
\cline { 2 - 3 } Variable & $\mathrm{B}$ & $\mathrm{C}$ \\
${\text { Target weight } \mathbf{1}^{1}}$ & & $1,807 \pm 50.1$ \\
Live wt (g) & $1,959 \pm 54.4$ & $1,288 \pm 38.3$ \\
Carcass wt (g) & $393.5 \pm 15.40$ & $407.8 \pm 15.95$ \\
Breast wt (g) & $214.5 \pm 6.76$ & $191.9 \pm 6.04$ \\
Thigh wt (g) & $174.9 \pm 4.23$ & $167.8 \pm 4.05$ \\
Drumstick wt (g) & $137.7 \pm 3.83$ & $132.0 \pm 3.68$ \\
Wing wt (g) & $69.9 \pm 0.67$ & $71.3 \pm 0.68$ \\
Carcass yield (\% LW) & $28.7 \pm 0.48^{\mathrm{b}}$ & $31.7 \pm 0.53^{\mathrm{a}}$ \\
Breast yield (\% CW) & $20.1 \pm 0.38^{\mathrm{b}}$ & $22.6 \pm 0.43^{\mathrm{a}}$ \\
Breast yield (\% LW) & $15.7 \pm 0.39$ & $14.9 \pm 0.37$ \\
Thigh yield (\% CW) & $10.9 \pm 0.27$ & $10.6 \pm 0.26$ \\
Thigh yield (\% LW) & $12.8 \pm 0.20$ & $13.0 \pm 0.20$ \\
Drumstick yield (\% CW) & $8.9 \pm 0.14$ & $9.3 \pm 0.14$ \\
Drumstick yield (\% LW) & $10.1 \pm 0.18$ & $10.2 \pm 0.19$ \\
Wing yield (\% CW) & $7.0 \pm 0.13$ & $7.3 \pm 0.13$ \\
Wing yield (\% LW) & &
\end{tabular}

Target weight $2^{4}$

\begin{tabular}{lcc}
\hline Live wt (g) & $3,288 \pm 74.5$ & $3,283 \pm 91.1$ \\
Carcass wt (g) & $2,411 \pm 58.6$ & $2,419 \pm 72.0$ \\
Breast wt (g) & $780.4 \pm 24.93$ & $850.2 \pm 33.28$ \\
Thigh wt (g) & $360.7 \pm 9.28$ & $341.9 \pm 10.77$ \\
Drumstick wt (g) & $303.5 \pm 5.99$ & $299.2 \pm 7.23$ \\
Wing wt (g) & $234.2 \pm 5.33$ & $219.2 \pm 6.11$ \\
Carcass yield (\% LW) & $73.4 \pm 0.57$ & $73.7 \pm 0.71$ \\
Breast yield (\% CW) & $32.3 \pm 0.44^{\mathrm{b}}$ & $35.1 \pm 0.59^{\mathrm{a}}$ \\
Breast yield (\% LW) & $23.7 \pm 0.37^{\mathrm{b}}$ & $25.9 \pm 0.49^{\mathrm{a}}$ \\
Thigh yield (\% CW) & $14.9 \pm 0.30$ & $14.1 \pm 0.35$ \\
Thigh yield (\% LW) & $11.0 \pm 0.22$ & $10.4 \pm 0.26$ \\
Drumstick yield (\% CW) & $12.6 \pm 0.16$ & $12.4 \pm 0.19$ \\
Drumstick yield (\% LW) & $9.2 \pm 0.11$ & $9.1 \pm 0.14$ \\
Wing yield (\% CW) & $9.7 \pm 0.14$ & $9.1 \pm 0.16$ \\
Wing yield (\% LW) & $7.1 \pm 0.11$ & $6.7 \pm 0.12$
\end{tabular}

At Target Weights 1 and 2, CONV strains were 34 and $48 \mathrm{~d}$, respectively.

${ }^{\mathrm{a}-\mathrm{b}}$ Different superscripts within the same row represent differences among categories $(P<0.05)$.

${ }^{1}$ Number of birds per strain at target weight 1 : Strain B: $\mathrm{n}=32$; Strain $\mathrm{C}: \mathrm{n}=32$.

${ }^{2}$ Yields calculated relative to live weight obtained $1 \mathrm{~d}$ before processing.

${ }^{3}$ Yields calculated as a ratio to the eviscerated carcass weight.

${ }^{4}$ Number of birds per strain at target weight 2: Strain B: $n=48$; Strain $\mathrm{C}: \mathrm{n}=32$.

relative to the carcass weight than males $(28.2 \pm 0.11 \%$ vs. $27.7 \pm 0.11 \% ; P<0.001)$, a category by sex interaction was present $(P=0.035)$. Sex did not affect breast yield in CONV and MOD strains, but females had greater breast yields than males for FAST and SLOW strains.

Breast yield was affected by strain $(P<0.001)$ in all categories (Tables $2-5$ ). For CONV strains, breast yield was greater in strain C vs. B at both TWs (Table 2). For FAST strains, strain $\mathrm{F}$ had the greatest breast yield at both TWs (Table 3). However, at TW 1, strain M had the lowest breast yield and strains I and G had similar and intermediate breast yields. At TW 2, this difference disappeared and strain $M$ had similar breast yield to strains $\mathrm{G}$ and I. For MOD strains, strain E had lower breast yield (relative to both carcass and LW) than strain $\mathrm{O}$ at TW 1, which was also observed at TW 2 for the values relative to $\mathrm{LW}$, while breast yield relative to the carcass weight was similar among the MOD strains (Table 4). For SLOW, strain D had the lowest breast yield at both TWs (Table 5).

Thigh Yield. Similar to breast yield, thigh yield differed among categories, following growth rates $(P<$ 0.001; Table 1). However, an opposite pattern was observed, with lower thigh yields as growth rate increased. At TW 1, CONV and FAST had greater thigh yield (relative to carcass weight) than SLOW, while at TW 2, CONV had the lowest thigh yield (relative to carcass weight and LW). Although at TW 1 thigh yield relative to the LW was not significant among the categories, it followed a similar numerical pattern to the values relative to carcass weight. A decrease in thigh yield relative to carcass weight was observed from TW 1 to TW $2(15.9 \pm 0.10$ vs. $15.5 \pm$ $0.09 \% ; P=0.062)$ with no interactions present between target weight and category $(P=0.513)$ or target weight and strain $(P=0.755)$.

Overall, males had greater thigh yield than females $(15.8 \pm 0.09$ vs. $15.5 \pm 0.09 \% ; P=0.027)$ with no interactions between category and sex $(P=0.748)$ or strain and $\operatorname{sex}(P=0.668)$. Within categories, only FAST strains differed in thigh yield. Strain F had lower thigh yield relative to carcass weight than strains $\mathrm{G}$ and I strains at TW 2, with no strain differences at TW 1 (Table 3).

Drumstick Yield. Drumstick yield was impacted by category, following a similar pattern as thigh yield, with higher drumstick yield associated with lower growth rate $(P<0.001$; Table 1$)$. At TW $1, \mathrm{CONV}$ strains had drumstick yields relative to carcass weight similar to FAST, yet lower than MOD and SLOW strains. At TW 2 , drumstick yield relative to the carcass weight was different among all the categories, with CONV $<$ FAST $<$ MOD < SLOW, with a similar pattern observed for the yield relative to the $\mathrm{LW}$, although CONV did not differ from FAST, but was lower than MOD and SLOW $(P<$ 0.001 , Table 1) There was a decrease in drumstick yield relative to carcass yield from TW 1 to TW 2 (13.4 \pm 0.05 vs. $13.0 \pm 0.49 \% ; P<0.001)$ with no interactions present between category and target weight $(P=0.798)$ or strain and target weight $(P=0.911)$. For FAST birds (Table 3), strain F had the lowest drumstick yield at TW 1, with the same pattern observed at TW 2 for the drumstick yield relative to the LW, whereas drumstick yield relative to carcass weight for strain $\mathrm{F}$ was lower than yields for strains $\mathrm{G}$ and $\mathrm{M}$, yet similar to strain I. For SLOW birds (Table 5), strain D had greater drumstick yield relative to carcass weight than strains $\mathrm{J}$ and $\mathrm{N}$ at both TWs.

While males had greater drumstick yields than females $(13.6 \pm 0.08 \%$ vs. $12.9 \pm 0.04 \%$; $P<0.001)$, a strain by sex interaction $(P=0.004)$ was present. For CONV birds, strain $\mathrm{B}$ males had greater drumstick yields relative to carcass weight than strain B females, with no sex differences for drumstick yields in strain C. For FAST strains, F females had lower drumstick yield compared to other females, while among FAST males, 
Incidence of wooden breast- Target weight $1^{1}$

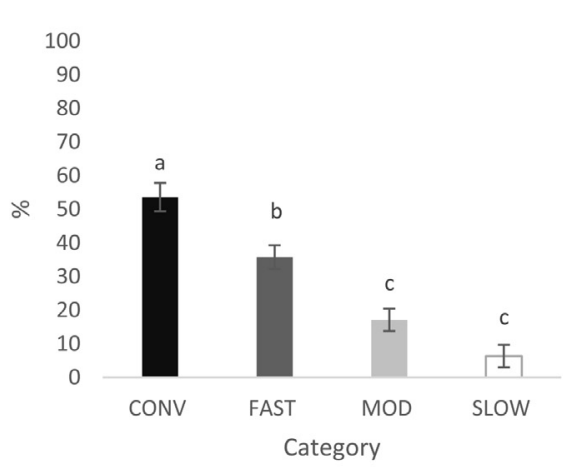

Incidence of wooden breast- Target weight $2^{2}$

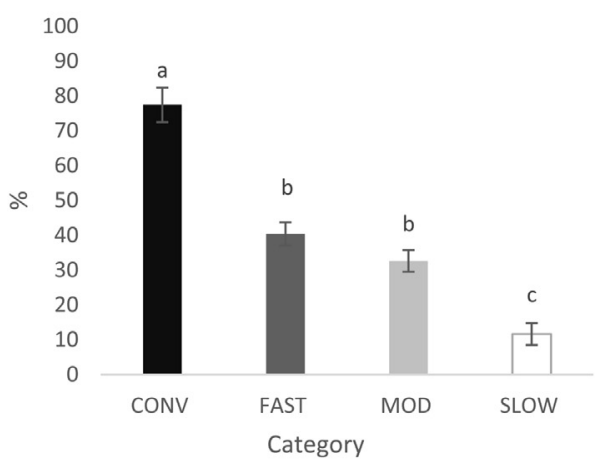

Incidence of white striping- Target weight $1^{3}$

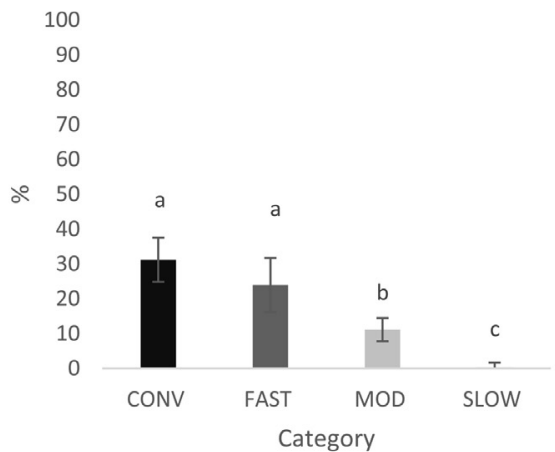

Incidence of white striping- Target weight $2^{4}$

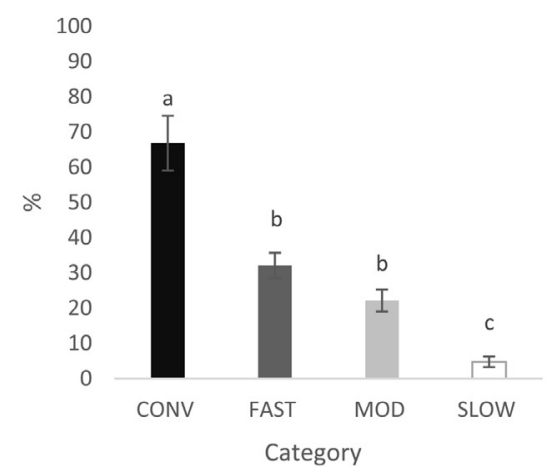

Figure 1. Effects of category on the total incidence of breast fillets presenting wooden breast ${ }^{1,2}$ and white striping ${ }^{3,4}$ at Target Weights 1 and 2 (LS-means \pm SEM). At Target Weight 1, CONV and other categories were 34 and $48 \mathrm{~d}$ of age, respectively. At Target Weight 2 , CONV and other categories were 48 and $62 \mathrm{~d}$, respectively.

${ }^{\mathrm{a}-\mathrm{c}}$ Different superscripts represent differences among categories $(P<0.05)$.

${ }^{1}$ Number of birds per category at target weight 1 : CONV: $\mathrm{n}=104 ;$ FAST: $\mathrm{n}=156 ;$ MOD: $\mathrm{n}=175 ;$ SLOW: $\mathrm{n}=173$

${ }^{2}$ Number of birds per category at target weight 2: CONV: $\mathrm{n}=80$; FAST: $\mathrm{n}=176$; MOD: $\mathrm{n}=196$; SLOW: $\mathrm{n}=198$.

${ }^{3}$ Number of birds per category at target weight 1 : CONV: $\mathrm{n}=91$; FAST: $\mathrm{n}=124$; MOD: $\mathrm{n}=159$; SLOW $\mathrm{n}:=125$.

${ }^{4}$ Number of birds per category at target weight 2 : CONV: $\mathrm{n}=64$ FAST: $\mathrm{n}=132$; MOD: $\mathrm{n}=171$; SLOW: $\mathrm{n}=162$.

strain did not affect drumstick yield. For MOD category strains, males had greater drumstick yields relative to carcass weight than females for strains $\mathrm{E}, \mathrm{H}$, and $\mathrm{S}$ with no sex differences in drumstick yield for strain $\mathrm{O}$ birds. Drumstick yields (relative to carcass weight) for SLOW strains females did not differ, while strain D males had greater drumstick yields than strains $\mathrm{J}$ and $\mathrm{N}$ males (data not shown).

Wing Yield. Category affected wing yield at both TWs $(P<0.001$; Table 1$)$. At TW 1, CONV and FAST had similar wing yields (relative to the carcass weight) that were lower than MOD and SLOW. A similar pattern was observed for wing yield relative to the LW, but CONV had the lowest yield, while MOD and SLOW had the highest wing yield, with FAST being intermediate. At TW 2, a significant higher wing yield was observed as the growth rate decreased $(\mathrm{CONV}<\mathrm{FAST}<\mathrm{MOD}<$ SLOW). Wing yield decreased as birds aged (TW $1=$ $10.8 \pm 0.05 \%$, TW $2=10.1 \pm 0.04 \% ; P<0.001)$ with no interactions present between target weight and category $(P=0.599)$ or target weight and strain $(P=0.128)$. Sex did not affect wing yield $(P=0.370)$ with no category by sex interaction $(P=0.290)$ present.

Wing yield was affected by strain within categories $(P<0.001)$ at both TWs. For FAST birds (Table 3), strain $\mathrm{F}$ had lower wing yield (relative to carcass weight) than strain $\mathrm{M}$ at $\mathrm{TW} 1$, while strains $\mathrm{G}$ and I were similar and did not differ from strains $\mathrm{F}$ and M, but this difference disappeared at TW 2 (Table 3). For SLOW birds (Table 5), no differences in wing yield was observed at TW 1, but at TW 2, strain J had lower wing yield (relative to the carcass weight and LW) than strains D and K. A strain by sex interaction was present $(P<0.040)$ involving FAST and SLOW strains. For FAST birds, strain differences in wing yield (relative to the carcass weight) were found for females, but not for males. For SLOW birds, strain $\mathrm{J}$ males had greater wing yield (relative to carcass weight) than strain $\mathrm{J}$ females while for the remaining SLOW strains, females and males had similar wing yields (data not shown).

\section{Incidence and Severity of Myopathies}

Total Incidence of WB and WS. The incidence of WB differed by category, target weight, strain, and sex $(P<$ 0.001). Overall, the incidence of WB increased from TW 1 to TW 2 ( $28.2 \pm 1.81 \%$ of breast fillets scored vs. 40.5 $\pm 1.86 \%$ of breast fillets scored; $P<0.001)$ and males 
Table 3. Mean values (LS-means \pm SEM) for live weight (LW), carcass weight (CW), and cut-up yields among FAST strains of broiler chickens at Target Weights 1 and 2.

\begin{tabular}{|c|c|c|c|c|}
\hline \multirow{2}{*}{$\begin{array}{l}\text { Variable } \\
\text { Target weight } \mathbf{1}^{1}\end{array}$} & \multicolumn{4}{|c|}{ Strain } \\
\hline & $\mathrm{F}$ & G & I & $\mathrm{M}$ \\
\hline Live wt (g) & $2,522 \pm 71.0$ & $2,338 \pm 53.2$ & $2,402 \pm 54.7$ & $2,464 \pm 68.8$ \\
\hline Carcass wt (g) & $1,851 \pm 56.0$ & $1,659 \pm 40.5$ & $1,726 \pm 42.4$ & $1,716 \pm 51.5$ \\
\hline Breast wt (g) & $621.2 \pm 24.71^{\mathrm{a}}$ & $448.0 \pm 14.76^{\mathrm{b}}$ & $462.9 \pm 14.87^{\mathrm{b}}$ & $425.8 \pm 16.78^{b}$ \\
\hline Thigh wt (g) & $274.5 \pm 8.89$ & $271.1 \pm 7.03$ & $276.1 \pm 7.17$ & $271.9 \pm 8.68$ \\
\hline Drumstick wt (g) & $232.9 \pm 5.77$ & $223.7 \pm 4.44$ & $232.3 \pm 4.61$ & $236.0 \pm 5.77$ \\
\hline Wing wt $(\mathrm{g})$ & $185.3 \pm 5.27$ & $176.7 \pm 4.04$ & $181.3 \pm 4.15$ & $190.2 \pm 5.35$ \\
\hline Carcass yield $(\% \mathrm{LW})^{2}$ & $73.4 \pm 0.72^{\mathrm{a}}$ & $70.9 \pm 0.56^{\mathrm{b}}$ & $71.7 \pm 0.57^{\mathrm{ab}}$ & $69.6 \pm 0.68^{\mathrm{b}}$ \\
\hline Breast yield $(\% \mathrm{CW})^{3}$ & $33.5 \pm 0.58^{\mathrm{a}}$ & $27.0 \pm 0.37^{\mathrm{b}}$ & $26.9 \pm 0.38^{\mathrm{b}}$ & $24.9 \pm 0.42^{\mathrm{c}}$ \\
\hline Breast yield (\% LW) & $24.6 \pm 0.48^{\mathrm{a}}$ & $19.2 \pm 0.30^{\mathrm{b}}$ & $19.2 \pm 0.31^{\mathrm{b}}$ & $17.3 \pm 0.33^{\mathrm{c}}$ \\
\hline Thigh yield (\% CW) & $14.8 \pm 0.38$ & $16.3 \pm 0.34$ & $16.0 \pm 0.33$ & $15.8 \pm 0.40$ \\
\hline Thigh yield ( $\%$ LW) & $10.9 \pm 0.26$ & $11.6 \pm 0.24$ & $11.5 \pm 0.23$ & $11.0 \pm 0.27$ \\
\hline Drumstick yield (\% CW) & $12.6 \pm 0.20^{\mathrm{b}}$ & $13.5 \pm 0.17^{\mathrm{a}}$ & $13.5 \pm 0.17^{\mathrm{a}}$ & $13.8 \pm 0.22^{\mathrm{a}}$ \\
\hline Drumstick yield (\% LW) & $9.2 \pm 0.14^{\mathrm{b}}$ & $9.6 \pm 0.12^{\mathrm{a}}$ & $9.7 \pm 0.12^{\mathrm{a}}$ & $9.6 \pm 0.15^{\mathrm{a}}$ \\
\hline Wing yield (\% CW) & $10.0 \pm 0.19^{\mathrm{b}}$ & $10.6 \pm 0.16^{\mathrm{ab}}$ & $10.5 \pm 0.16^{\mathrm{ab}}$ & $11.1 \pm 0.20^{\mathrm{a}}$ \\
\hline Wing yield (\% LW) & $7.3 \pm 0.14$ & $7.6 \pm 0.12$ & $7.5 \pm 0.11$ & $7.8 \pm 0.14$ \\
\hline
\end{tabular}

Target weight $2^{4}$

\begin{tabular}{|c|c|c|c|c|}
\hline Live wt (g) & $3,391 \pm 82.6$ & $3,357 \pm 76.1$ & $3,457 \pm 79.0$ & $3,464 \pm 98.3$ \\
\hline Carcass wt (g) & $2,579 \pm 67.7$ & $2,453 \pm 59.6$ & $2,487 \pm 61.07$ & $2,461 \pm 75.1$ \\
\hline Breast wt (g) & $886.1 \pm 30.54^{\mathrm{a}}$ & $695.3 \pm 22.22^{\mathrm{b}}$ & $692.1 \pm 22.34^{\mathrm{b}}$ & $677.7 \pm 27.17^{\mathrm{b}}$ \\
\hline Thigh wt (g) & $367.8 \pm 10.52$ & $394.5 \pm 10.15$ & $396.6 \pm 10.39$ & $380.7 \pm 12.51$ \\
\hline Drumstick wt (g) & $318.4 \pm 6.95$ & $322.4 \pm 6.36$ & $323.2 \pm 6.47$ & $326.8 \pm 8.18$ \\
\hline Wing wt (g) & $247.8 \pm 6.16$ & $247.4 \pm 5.63$ & $249.9 \pm 5.76$ & $250.7 \pm 7.20$ \\
\hline Carcass yield (\% LW) & $76.0 \pm 0.66^{\mathrm{a}}$ & $73.1 \pm 0.57^{\mathrm{b}}$ & $71.9 \pm 0.57^{\mathrm{b}}$ & $71.0 \pm 0.71^{\mathrm{b}}$ \\
\hline Breast yield (\% CW) & $34.3 \pm 0.52^{\mathrm{a}}$ & $28.3 \pm 0.39^{\mathrm{b}}$ & $27.8 \pm 0.39^{\mathrm{b}}$ & $27.5 \pm 0.48^{\mathrm{b}}$ \\
\hline Breast yield (\% LW) & $26.1 \pm 0.44^{\mathrm{a}}$ & $20.7 \pm 0.32^{\mathrm{b}}$ & $20.0 \pm 0.31^{\mathrm{b}}$ & $19.5 \pm 0.38^{\mathrm{b}}$ \\
\hline Thigh yield (\% CW) & $14.2 \pm 0.33^{\mathrm{b}}$ & $16.1 \pm 0.33^{\mathrm{a}}$ & $16.0 \pm 0.33^{\mathrm{a}}$ & $15.5 \pm 0.40^{\mathrm{ab}}$ \\
\hline Thigh yield (\% LW) & $10.8 \pm 0.24$ & $11.7 \pm 0.24$ & $11.5 \pm 0.23$ & $11.0 \pm 0.28$ \\
\hline Drumstick yield (\% CW) & $12.2 \pm 0.17^{\mathrm{b}}$ & $13.1 \pm 0.17^{\mathrm{a}}$ & $13.0 \pm 0.16^{\mathrm{ab}}$ & $13.3 \pm 0.21^{\mathrm{a}}$ \\
\hline Drumstick yield (\% LW) & $9.3 \pm 0.12^{\mathrm{c}}$ & $9.6 \pm 0.12^{\mathrm{b}}$ & $9.3 \pm 0.12^{\mathrm{ab}}$ & $9.4 \pm 0.15^{\mathrm{a}}$ \\
\hline Wing yield (\% CW) & $9.5 \pm 0.16$ & $10.1 \pm 0.15$ & $10.1 \pm 0.15$ & $10.2 \pm 0.19$ \\
\hline Wing yield (\% LW) & $7.2 \pm 0.12$ & $7.4 \pm 0.11$ & $7.2 \pm 0.11$ & $7.2 \pm 0.14$ \\
\hline
\end{tabular}

\footnotetext{
At Target Weight 1 and 2, FAST strains were 48 and $62 \mathrm{~d}$ of age, respectively.

${ }^{\mathrm{a}-\mathrm{b}}$ Different superscripts within the same row represent differences among categories $(P<0.05)$.

${ }^{1}$ Number of birds per strain at target weight 1: Strain F: $\mathrm{n}=30$; Strain G: $\mathrm{n}=47$; Strain I: $\mathrm{n}=47$; Strain M: $\mathrm{n}=31$.

${ }^{2}$ Yields calculated relative to live weight obtained one d before processing.

${ }^{3}$ Yields calculated as a ratio to the eviscerated carcass weight.

${ }^{4}$ Number of birds per strain at target weight 2: Strain F: $\mathrm{n}=38$; Strain G: $\mathrm{n}=48$; Strain I: $\mathrm{n}=46$; Strain M: $\mathrm{n}=29$.
}

had greater incidence of WB than females $(41.9 \pm 1.77 \%$ of breast fillets scored vs. $26.8 \pm 1.76 \%$ of breast fillets scored; $P<0.001)$. However, including BW as a covariate eliminated differences in WB incidence between TW $(P=0.249)$ and between sex $(P=0.155)$.

A category by target weight interaction was found $(P=0.048$; Figure 1). At both TWs, CONV strains had the greatest incidence of WB. However, at TW 1, WB incidence for FAST exceeded MOD and SLOW, with no differences in WB incidence between FAST and MOD strains at TW 2.

For CONV birds, strain $\mathrm{C}$ had a greater incidence of WB than strain B at TW 1, but this difference disappeared at TW 2 (Figure 2). For FAST birds, strain F had the greatest incidence of WB at both TWs (Figure 2). When using BW as a covariate, CONV birds still had the greatest incidence of WB compared to other categories and strain $\mathrm{F}$ had the greatest incidence of WB among FAST strains (data not shown).

Similar to WB incidence, category, target weight, strain, and sex affected the total incidence of WS $(P<$ 0.001). When BW was included as a covariate, the effect of sex disappeared $(P=0.410)$. While incidence of WS increased as birds grew from TW1 to TW 2 $(16.6 \pm 2.04 \%$ of breast fillets scored vs. $31.4 \pm 2.27 \%$ of breast fillets scored; $P<0.001$ ), a target weight by category interaction was observed $(P=0.018$; Figure 1$)$. Breasts from CONV and FAST had similar incidence of WS at TW 1, which was greater than MOD and SLOW. However, at TW 2, CONV had the highest and SLOW had lowest incidence of WS, while MOD and FAST had intermediate values. When differences in BW were considered, the effect of target weight on WS disappeared. In contrast, category $(P=0.036)$ and strain $(P<0.001)$ still influenced the incidence of WS, with CONV having the greatest percentage of WS across categories. Strains $\mathrm{C}$ and F still had more breasts exhibiting WS among CONV and FAST strains, respectively, while there were no differences among the strains in other categories on WS incidence (data not shown). Strain F had the greatest incidence of WS among FAST strains at both TWs (Figure 2). WS incidence did not differ among CONV, MOD strains or SLOW strains. 
Table 4. Mean values (LS-means \pm SEM) for live weight (LW), carcass weight (CW), and cut-up yields among MOD strains of broiler chickens at Target Weights 1 and 2 .

\begin{tabular}{|c|c|c|c|c|}
\hline \multirow{2}{*}{$\begin{array}{l}\text { Variable } \\
\text { Target weight } \mathbf{1}^{1} \\
\end{array}$} & \multicolumn{4}{|c|}{ Strain } \\
\hline & $\mathrm{E}$ & $\mathrm{H}$ & $\mathrm{O}$ & S \\
\hline Live wt $(\mathrm{g})$ & $2,506 \pm 56.8^{\mathrm{a}}$ & $2,321 \pm 53.8^{\mathrm{ab}}$ & $2,365 \pm 53.8^{\mathrm{ab}}$ & $2,208 \pm 50.2^{\mathrm{b}}$ \\
\hline Carcass wt (g) & $1,749 \pm 42.5$ & $1,641 \pm 48.9$ & $1,679 \pm 41.0$ & $1,580 \pm 38.6$ \\
\hline Breast wt $(\mathrm{g})$ & $451.3 \pm 14.42$ & $439.8 \pm 17.21$ & $463.1 \pm 14.87$ & $419.9 \pm 13.49$ \\
\hline Thigh wt (g) & $284.0 \pm 7.31$ & $257.8 \pm 8.12$ & $272.3 \pm 7.07$ & $251.1 \pm 6.52$ \\
\hline Drumstick wt (g) & $238.1 \pm 4.69^{\mathrm{a}}$ & $224.2 \pm 5.41^{\mathrm{ab}}$ & $224.2 \pm 4.46^{\mathrm{ab}}$ & $213.1 \pm 4.24^{\mathrm{b}}$ \\
\hline Wing wt (g) & $194.6 \pm 4.43^{\mathrm{a}}$ & $181.5 \pm 5.06^{\mathrm{ab}}$ & $180.7 \pm 4.13^{\mathrm{ab}}$ & $173.8 \pm 3.98^{\mathrm{b}}$ \\
\hline Carcass yield $(\% \mathrm{LW})^{2}$ & $69.8 \pm 0.54$ & $70.7 \pm 0.67$ & $71.0 \pm 0.56$ & $71.5 \pm 0.56$ \\
\hline Breast yield $(\% \mathrm{CW})^{3}$ & $25.8 \pm 0.35^{\mathrm{b}}$ & $26.8 \pm 0.45^{\mathrm{ab}}$ & $27.6 \pm 0.38^{\mathrm{a}}$ & $26.6 \pm 0.37^{\mathrm{ab}}$ \\
\hline Breast yield (\% LW) & $18.0 \pm 0.27^{\mathrm{b}}$ & $18.9 \pm 0.36^{\mathrm{ab}}$ & $19.6 \pm 0.31^{\mathrm{a}}$ & $19.0 \pm 0.29^{\mathrm{ab}}$ \\
\hline Thigh yield (\% CW) & $16.2 \pm 0.33$ & $15.7 \pm 0.39$ & $16.2 \pm 0.34$ & $15.9 \pm 0.33$ \\
\hline Thigh yield (\% LW) & $11.3 \pm 0.23$ & $11.0 \pm 0.27$ & $11.5 \pm 0.23$ & $11.4 \pm 0.23$ \\
\hline Drumstick yield (\% CW) & $13.6 \pm 0.17$ & $13.7 \pm 0.21$ & $13.4 \pm 0.17$ & $13.5 \pm 0.17$ \\
\hline Drumstick yield (\% LW) & $9.5 \pm 0.12$ & $9.7 \pm 0.15$ & $9.5 \pm 0.12$ & $9.6 \pm 0.12$ \\
\hline Wing yield $(\% \mathrm{CW})$ & $11.1 \pm 0.16$ & $11.1 \pm 0.20$ & $10.8 \pm 0.16$ & $11.0 \pm 0.16$ \\
\hline Wing yield (\% LW) & $7.8 \pm 0.12$ & $7.8 \pm 0.14$ & $7.6 \pm 0.11$ & $7.9 \pm 0.12$ \\
\hline
\end{tabular}

\section{Target weight $2^{4}$}

\begin{tabular}{|c|c|c|c|c|}
\hline Live wt $(\mathrm{g})$ & $3,285 \pm 74.5$ & $3,135 \pm 73.7$ & $3,252 \pm 73.7$ & $3,059 \pm 69.3$ \\
\hline Carcass wt (g) & $2,387 \pm 58.0$ & $2,261 \pm 57.2$ & $2,387 \pm 58.0$ & $2,226 \pm 54.1$ \\
\hline Breast wt (g) & $638.7 \pm 20.42$ & $620.2 \pm 20.59$ & $681.8 \pm 21.78$ & $630.7 \pm 20.15$ \\
\hline Thigh wt (g) & $385.0 \pm 9.90$ & $349.7 \pm 9.49$ & $372.3 \pm 9.58$ & $360.9 \pm 9.28$ \\
\hline Drumstick wt (g) & $319.6 \pm 6.31$ & $299.3 \pm 6.29$ & $314.1 \pm 6.20$ & $295.4 \pm 5.83$ \\
\hline Wing wt (g) & $247.9 \pm 5.64$ & $237.9 \pm 5.68$ & $243.2 \pm 5.54$ & $227.0 \pm 5.17$ \\
\hline Carcass yield (\% LW) & $72.6 \pm 0.57$ & $72.1 \pm 0.59$ & $73.4 \pm 0.57$ & $72.8 \pm 0.57$ \\
\hline Breast yield (\% CW) & $26.8 \pm 0.37$ & $27.4 \pm 0.40$ & $28.6 \pm 0.39$ & $28.3 \pm 0.39$ \\
\hline Breast yield (\% LW) & $19.4 \pm 0.30^{\mathrm{b}}$ & $19.7 \pm 0.32^{\mathrm{ab}}$ & $21.0 \pm 0.32^{\mathrm{a}}$ & $20.6 \pm 0.32^{\mathrm{ab}}$ \\
\hline Thigh yield (\% CW) & $16.1 \pm 0.33$ & $15.4 \pm 0.33$ & $15.6 \pm 0.32$ & $16.2 \pm 0.33$ \\
\hline Thigh yield (\% LW) & $11.7 \pm 0.23$ & $11.1 \pm 0.24$ & $11.4 \pm 0.23$ & $11.8 \pm 0.24$ \\
\hline Drumstick yield (\% CW) & $13.4 \pm 0.17$ & $13.2 \pm 0.17$ & $13.2 \pm 0.17$ & $13.3 \pm 0.17$ \\
\hline Drumstick yield (\% LW) & $9.7 \pm 0.12$ & $9.5 \pm 0.13$ & $9.7 \pm 0.12$ & $9.7 \pm 0.12$ \\
\hline Wing yield (\% CW) & $10.4 \pm 0.15$ & $10.5 \pm 0.17$ & $10.2 \pm 0.15$ & $10.2 \pm 0.15$ \\
\hline Wing yield (\% LW) & $7.5 \pm 0.11$ & $7.6 \pm 0.12$ & $7.5 \pm 0.11$ & $7.4 \pm 0.11$ \\
\hline
\end{tabular}

\footnotetext{
At Target Weight 1 and 2, MOD strains were 48 and $62 \mathrm{~d}$ of age, respectively.

a-b Different superscripts within the same row represent differences among categories $(P<0.05)$.

${ }^{1}$ Number of birds per strain at target weight 1: Strain $\mathrm{E}: \mathrm{n}=48$; Strain H: $\mathrm{n}=32$; Strain O: $\mathrm{n}=47$; Strain S: $\mathrm{n}=47$.

${ }^{2}$ Yields calculated relative to live weight obtained $1 \mathrm{~d}$ before processing.

${ }^{3}$ Yields calculated as a ratio to the eviscerated carcass weight.

${ }^{4}$ Number of birds per strain at target weight 2: Strain E: $\mathrm{n}=48$; Strain H: $\mathrm{n}=42$; Strain O: $\mathrm{n}=48$; Strain S: $\mathrm{n}=48$.
}

Moderate-Severe WB and WS. While breast fillets affected by moderate to severe scores differed by category $(P<0.001$; Figure 3$)$ at both TWs, incidence increased from TW 1 to 2 (TW1: $15.1 \pm 1.37 \%$ of breast fillets scored, TW 2: $25.1 \pm 1.41 \%$ of breast fillets scored; $P<0.001)$. However, there was a TW by category interaction $(P<0.001)$ for moderate-severe WB due to a similar incidence in CONV and FAST at TW 1, while at TW 2 CONV had over twice the incidence of moderatesevere WB than FAST.

Males had a greater incidence of moderate-severe WB than females (males: $25.9 \pm 1.36 \%$ of breast fillets scored; females: $14.4 \pm 1.35 \%$ of breast fillets scored; $P$ $<0.001)$, but sex interacted with category $(P=0.008)$. Males had a greater incidence of moderate-severe WB than females in all the categories, except among SLOW birds, which were not affected by sex (data not shown).

Incidence of moderate-severe WB was greatest in strain $\mathrm{C}$ for $\mathrm{CONV}$ birds (Figure 4) and strain $\mathrm{F}$ for FAST birds. Incidence of moderate-severe WB was similar among strains for MOD birds and SLOW birds.
Incidence of moderate-severe WS increased from TW 1 to TW $2(6.1 \pm 1.27 \%$ of breast fillets scored vs. $12.2 \pm$ $1.32 \%$ of breast fillets scored; $P=<0.002)$. A TW by category interaction $(P=0.005$, Figure 3$)$ in moderate-severe WS was due to similar incidence of moderate-severe scores for CONV and FAST at TW 1, while incidence of moderate-severe scores for WS was greater in CONV vs. FAST at TW 2. Overall, males had greater incidence of moderate-severe WS than females (males: $11.2 \pm 1.13 \%$ of breast fillets scored; females: $7.1 \pm 1.11 \%$ of breast fillets scored; $P=0.001$ ). Strain did not affect the incidence of moderate-severe for WS in CONV strains at TW 1, but strain C had more moderate-severe WS than strain B at TW 2 (Figure 4). Strain F had a greater percentage of moderatesevere WS compared to other FAST strains at both TWs.

Average Scores for $W B$ and $W S$. The average WB score increased from TW 1 to TW $2(0.50 \pm 0.037$ vs. $0.79 \pm 0.039 ; P<0.001)$. A TW by category interaction $(P=0.001$, Figure 5$)$ was due to similar average WB scores for CONV and FAST at TW 1, while average WB score was greater in CONV vs. FAST at TW 2. 
Table 5. Mean values (LS-means \pm SEM) for live weight (LW), carcass weight (CW), and cut-up yields among SLOW strains of broiler chickens at Target Weights 1 and 2.

\begin{tabular}{|c|c|c|c|c|}
\hline \multirow{2}{*}{$\begin{array}{l}\text { Variable } \\
\text { Target weight } \mathbf{1}^{1}\end{array}$} & \multicolumn{4}{|c|}{ Strain } \\
\hline & $\mathrm{D}$ & $\mathrm{J}$ & K & $\mathrm{N}$ \\
\hline Live wt (g) & $2,025 \pm 56.2$ & $2,072 \pm 47.2$ & $1,942 \pm 44.2$ & $1,967 \pm 44.8$ \\
\hline Carcass wt $(\mathrm{g})$ & $1,352 \pm 40.3$ & $1,444 \pm 35.3$ & $1,355 \pm 33.1$ & $1,346 \pm 33.0$ \\
\hline Breast wt (g) & $281.9 \pm 11.03^{\mathrm{c}}$ & $380.3 \pm 12.21^{\mathrm{a}}$ & $324.9 \pm 10.43^{\mathrm{bc}}$ & $341.8 \pm 10.98^{\mathrm{ab}}$ \\
\hline Thigh wt (g) & $228.0 \pm 7.18$ & $233.3 \pm 6.05$ & $223.1 \pm 5.79$ & $223.7 \pm 5.80$ \\
\hline Drumstick wt (g) & $198.9 \pm 4.80$ & $197.7 \pm 3.93$ & $189.7 \pm 3.77$ & $184.0 \pm 3.66$ \\
\hline Wing wt $(\mathrm{g})$ & $158.4 \pm 4.42$ & $160.2 \pm 3.67$ & $160.9 \pm 3.68$ & $152.5 \pm 3.49$ \\
\hline Carcass yield $(\% \mathrm{LW})^{2}$ & $66.8 \pm 0.64^{\mathrm{b}}$ & $69.7 \pm 0.55^{\mathrm{a}}$ & $69.8 \pm 0.55^{\mathrm{a}}$ & $68.4 \pm 0.54^{\mathrm{ab}}$ \\
\hline Breast yield $(\% \mathrm{CW})^{3}$ & $20.8 \pm 0.35^{\mathrm{c}}$ & $26.3 \pm 0.36^{\mathrm{a}}$ & $24.0 \pm 0.33^{\mathrm{b}}$ & $25.5 \pm 0.36^{\mathrm{ab}}$ \\
\hline Breast yield (\% LW) & $13.9 \pm 0.26^{\mathrm{c}}$ & $18.3 \pm 0.29^{\mathrm{a}}$ & $16.7 \pm 0.26^{\mathrm{b}}$ & $17.4 \pm 0.27^{\mathrm{ab}}$ \\
\hline Thigh yield (\% CW) & $16.9 \pm 0.42$ & $16.1 \pm 0.33$ & $16.5 \pm 0.34$ & $16.7 \pm 0.35$ \\
\hline Thigh yield ( $\%$ LW) & $11.3 \pm 0.28$ & $11.2 \pm 0.23$ & $11.5 \pm 0.23$ & $11.4 \pm 0.23$ \\
\hline Drumstick yield (\% CW) & $14.7 \pm 0.23^{\mathrm{a}}$ & $13.7 \pm 0.17^{\mathrm{b}}$ & $14.0 \pm 0.18^{\mathrm{ab}}$ & $13.7 \pm 0.18^{\mathrm{b}}$ \\
\hline Drumstick yield (\% LW) & $9.8 \pm 0.15$ & $9.5 \pm 0.12$ & $9.8 \pm 0.12$ & $9.4 \pm 0.12$ \\
\hline Wing yield (\% CW) & $11.7 \pm 0.21$ & $11.1 \pm 0.17$ & $11.9 \pm 0.18$ & $11.3 \pm 0.17$ \\
\hline Wing yield (\% LW) & $7.8 \pm 0.14$ & $7.8 \pm 0.14$ & $8.3 \pm 0.13$ & $7.7 \pm 0.12$ \\
\hline
\end{tabular}

Target weight $2^{4}$

\begin{tabular}{|c|c|c|c|c|}
\hline Live wt (g) & $2,805 \pm 65.1$ & $2,936 \pm 66.5$ & $2,753 \pm 62.7$ & $2,746.1 \pm 62.2$ \\
\hline Carcass wt (g) & $1,951 \pm 48.7$ & $2,134 \pm 51.9$ & $1,924 \pm 47.0$ & $1,974 \pm 47.9$ \\
\hline Breast wt (g) & $429.4 \pm 14.07^{\mathrm{c}}$ & $594.3 \pm 18.99^{\mathrm{a}}$ & $492.7 \pm 15.82^{\mathrm{bc}}$ & $512.3 \pm 16.37^{\mathrm{ab}}$ \\
\hline Thigh wt (g) & $326.8 \pm 8.75$ & $342.2 \pm 8.80$ & $320.6 \pm 8.32$ & $311.9 \pm 8.02$ \\
\hline Drumstick wt (g) & $274.0 \pm 5.66$ & $281.6 \pm 5.56$ & $266.7 \pm 5.30$ & $261.8 \pm 5.17$ \\
\hline Wing wt (g) & $221.9 \pm 5.21$ & $215.6 \pm 4.91$ & $220.6 \pm 5.05$ & $212.5 \pm 4.84$ \\
\hline Carcass yield (\% LW) & $69.5 \pm 0.57^{\mathrm{c}}$ & $72.7 \pm 0.57^{\mathrm{a}}$ & $69.9 \pm 0.55^{\mathrm{bc}}$ & $71.9 \pm 0.56^{\mathrm{ab}}$ \\
\hline Breast yield (\% CW) & $22.1 \pm 0.31^{\mathrm{c}}$ & $27.8 \pm 0.38^{\mathrm{a}}$ & $25.8 \pm 0.35^{\mathrm{b}}$ & $25.9 \pm 0.36^{\mathrm{b}}$ \\
\hline Breast yield (\% LW) & $15.3 \pm 0.25^{\mathrm{c}}$ & $20.2 \pm 0.31^{\mathrm{a}}$ & $17.9 \pm 0.28^{\mathrm{b}}$ & $18.7 \pm 0.29^{\mathrm{b}}$ \\
\hline Thigh yield (\% CW) & $16.8 \pm 0.36$ & $16.0 \pm 0.33$ & $16.8 \pm 0.35$ & $15.8 \pm 0.32$ \\
\hline Thigh yield (\% LW) & $11.7 \pm 0.24$ & $11.7 \pm 0.23$ & $11.7 \pm 0.24$ & $11.4 \pm 0.23$ \\
\hline Drumstick yield (\% CW) & $14.1 \pm 0.17^{\mathrm{a}}$ & $13.2 \pm 0.17^{\mathrm{b}}$ & $13.9 \pm 0.18^{\mathrm{ab}}$ & $13.3 \pm 0.17^{\mathrm{b}}$ \\
\hline Drumstick yield (\% LW) & $9.8 \pm 0.13$ & $9.6 \pm 0.12$ & $9.7 \pm 0.12$ & $9.5 \pm 0.12$ \\
\hline Wing yield (\% CW) & $11.4 \pm 0.17^{\mathrm{a}}$ & $10.0 \pm 0.15^{\mathrm{b}}$ & $11.5 \pm 0.17^{\mathrm{a}}$ & $10.8 \pm 0.16^{\mathrm{ab}}$ \\
\hline Wing yield (\% LW) & $7.9 \pm 0.13^{\mathrm{a}}$ & $7.3 \pm 0.11^{\mathrm{b}}$ & $8.0 \pm 0.12^{\mathrm{a}}$ & $7.7 \pm 0.12^{\mathrm{ab}}$ \\
\hline
\end{tabular}

\footnotetext{
At Target Weight 1 and 2, SLOW strains were 48 and $62 \mathrm{~d}$ of age, respectively.

${ }^{\text {a-c }}$ Different superscripts within the same row represent differences among categories $(P<0.05)$.

${ }^{1}$ Number of birds per strain at target weight 1: Strain D: $\mathrm{n}=32$; Strain J: $\mathrm{n}=47$; Strain K: $\mathrm{n}=47$; Strain N: $\mathrm{n}=47$.

${ }^{2}$ Yields calculated relative to live weight obtained $1 \mathrm{~d}$ before processing.

${ }^{3}$ Yields calculated as a ratio to the eviscerated carcass weight.

${ }^{4}$ Number of birds per strain at target weight 2: Strain D: $\mathrm{n}=44$; Strain J: $\mathrm{n}=48$; Strain K: $\mathrm{n}=47$; Strain N: $\mathrm{n}=48$.
}

Males had a greater average score for WB than females (males: $0.81 \pm 0.038$; females: $0.48 \pm 0.04 ; P<$ $0.001)$. However, there was an interaction between sex and category $(P<0.001)$, where average WB score was similar among females for MOD and SLOW, whereas among males MOD was greater than SLOW.

Strain C had a greater average WB score than strain B for CONV birds at both TWs (Figure 6). Strain F had the greatest average WB score compared to other FAST strains at both TWs (Figure 6). For SLOW birds, strain $\mathrm{N}$ had greater average WB score than strain D at TW 2 (Figure 6).

Average WS score increased from TW 1 to TW $2(0.25$ \pm 0.030 vs $0.50 \pm 0.034 ; P<0.001)$. A TW by category interaction $(P=0.001$, Figure 5$)$ was due to similar average WS scores between CONV and FAST, which exceeded similar values between MOD and SLOW at TW 1 while at TW 2, average WS score was higher as the growth rate increased, with CONV > FAST > MOD $>$ SLOW. Males had greater average WS scores than females (males: $0.48 \pm 0.030$; females: $0.27 \pm 0.030 ; P<$ $0.001)$. A sex by category $(P=0.004)$ interaction was due to similar average WS scores between CONV and
FAST females which exceeded similar values between MOD and SLOW females, while for males, average WS scores were significantly higher as the growth rate increased, with CONV > FAST $>$ MOD $>$ SLOW (data not shown).

Strain did not affect average WS score for CONV birds at TW 1, yet strain $\mathrm{C}$ had greater average WS scores than strain B at TW 2 (Figure 6). Strain F had a greater percentage of severe WS compared to other FAST strains at both TWs.

\section{Correlation Among Myopathies and Carcass Traits}

The relationships between the incidence of myopathies and processing traits (relative to the carcass weight) are shown in Table 6 . Live weight was weakly to moderately positively correlated $(P<0.010)$ with the incidence of WB and WS for all categories of strains. Similarly, for all categories, there was a positive weak to moderate correlation $(P<0.030)$ between carcass yield and incidence of WB, whereas carcass yield was weakly to strongly positively 


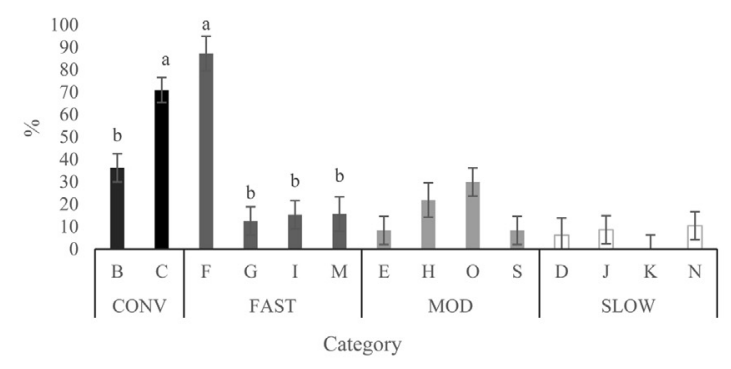

Incidence of wooden breast- Target weight $2^{2}$

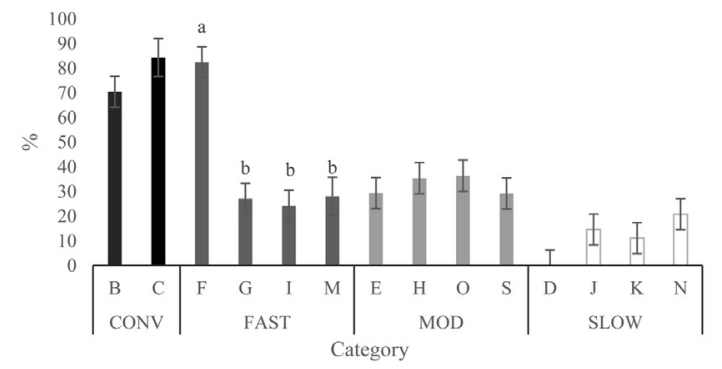

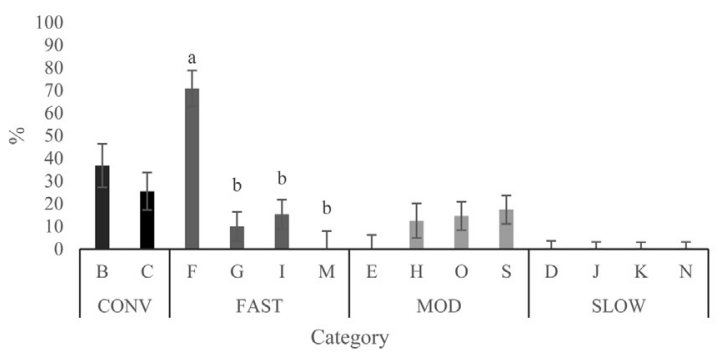

Incidence of white striping- Target weight $2^{4}$

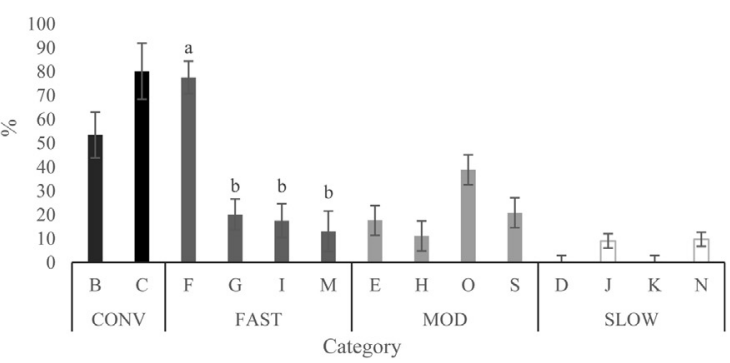

Figure 2. Effects of strains (within category) on the total incidence of breast fillets presenting wooden breast ${ }^{1,2}$ and white striping ${ }^{3,4}$ at Target Weights 1 and 2 (LS-means \pm SEM). At Target Weight 1, CONV and other categories were 34 and $48 \mathrm{~d}$ of age, respectively. At Target Weight 2 , CONV and other categories were 48 and $62 \mathrm{~d}$, respectively.

${ }^{\mathrm{a}-\mathrm{b}}$ Different superscripts within the same category represent differences among strains $(P<0.05)$.

${ }^{1}$ Number of birds per strain at target weight $1: \mathrm{B}: \mathrm{n}=52, \mathrm{C}: \mathrm{n}=52, \mathrm{~F}: \mathrm{n}=30, \mathrm{G}: \mathrm{n}=47, \mathrm{I}: \mathrm{n}=47, \mathrm{M}: \mathrm{n}=32, \mathrm{E}: \mathrm{n}=48, \mathrm{H}: \mathrm{n}=32, \mathrm{O}: \mathrm{n}=47, \mathrm{~S}$ : $\mathrm{n}=48 ; \mathrm{D}: \mathrm{n}=32 ; \mathrm{J}: \mathrm{n}=47, \mathrm{~K}: \mathrm{n}=47, \mathrm{~N}: \mathrm{n}=47$.

${ }^{2}$ Number of birds per strain at target weight $2: \mathrm{B}: \mathrm{n}=48, \mathrm{C}: \mathrm{n}=32, \mathrm{~F}: \mathrm{n}=52, \mathrm{G}: \mathrm{n}=48, \mathrm{I}: \mathrm{n}=47, \mathrm{M}: \mathrm{n}=29, \mathrm{E}: \mathrm{n}=48, \mathrm{H}: \mathrm{n}=52, \mathrm{O}: \mathrm{n}=48, \mathrm{~S}$ : $\mathrm{n}=48, \mathrm{D}: \mathrm{n}=55, \mathrm{~J}: \mathrm{n}=48, \mathrm{~K}: \mathrm{n}=47, \mathrm{~N}: \mathrm{n}=48$.

${ }^{3}$ Number of birds per strain at target weight $1: \mathrm{B}: \mathrm{n}=45, \mathrm{C}: \mathrm{n}=46, \mathrm{~F}: \mathrm{n}=25, \mathrm{G}: \mathrm{n}=39, \mathrm{I}: \mathrm{n}=39, \mathrm{M}: \mathrm{n}=21, \mathrm{E}: \mathrm{n}=47, \mathrm{H}: \mathrm{n}=24, \mathrm{O}: \mathrm{n}=44, \mathrm{~S}$ : $\mathrm{n}=44, \mathrm{D}: \mathrm{n}=26, \mathrm{~J}: \mathrm{n}=28, \mathrm{~K}: \mathrm{n}=39, \mathrm{~N}: \mathrm{n}=32$.

${ }^{4}$ Number of birds per strain at target weight $2: \mathrm{B}: \mathrm{n}=36, \mathrm{C}: \mathrm{n}=28, \mathrm{~F}: \mathrm{n}=42, \mathrm{G}: \mathrm{n}=41, \mathrm{I}: \mathrm{n}=31, \mathrm{M}: \mathrm{n}=18, \mathrm{E}: \mathrm{n}=40, \mathrm{H}: \mathrm{n}=48, \mathrm{O}: \mathrm{n}=44, \mathrm{~S}$ : $\mathrm{n}=39, \mathrm{D}: \mathrm{n}=45, \mathrm{~J}: \mathrm{n}=37, \mathrm{~K}: \mathrm{n}=44, \mathrm{~N}: \mathrm{n}=36$.

correlated $(P<0.028)$ with WS, depending on the category. Breast yield was also weakly to moderately positively correlated $(P<0.013)$ with the incidence of WB and WS across all categories. In contrast, there was a weak negative correlation between thigh yield and the incidence of WB for the FAST category $(P=0.007)$, while no significant correlations were found in the other categories. Drumstick yield was weakly and negatively correlated $(P=0.012)$ with the incidence of WB in the FAST group, whereas a negative weak correlation $(P<0.003)$ was found between drumstick yield and the incidence of WS in the CONV and FAST categories. Among FAST, MOD, and SLOW categories, wing yield and the incidence of WB were weakly to moderately negatively correlated $(P<$ $0.038)$, whereas there was a negative weak to moderate correlation $(P<0.007)$ between wing yield and WS incidence for FAST and MOD groups.

\section{DISCUSSION}

Selection for improved growth performance in fastgrowing strains of broiler chickens has been associated with changes in body composition and development of muscle disorders including WB and WS (Petracci et al., 2015; Barbut, 2019). Therefore, the use of slower-growing strain has been suggested as an alternative to decrease these myopathies (Petracci et al., 2019). However, there is little information on the incidence of myopathies in slower-growing strains with different growth rates and carcass traits than fast-growing strains. Therefore, this study investigated the differences in processing traits (weight and yield) and the incidence and severity of WB and WS in 14 strains of broiler chickens representing a wide range of growth rates. These strains were divided into 4 categories (CONV, FAST, MOD, and SLOW) based on the similarity of growth rates.

Slower-growing strains were hypothesized to have different carcass yields and composition along with fewer myopathies compared to fast-growing broiler chickens. Our findings demonstrate differences among categories for all carcass traits and the incidence and severity of muscle abnormalities. However, we also found differences within categories, indicating remarkable differences among strains, despite their similar growth rate.

\section{Processing Traits - Absolute Weight and Percentage Yield}

The differences in BW among the categories were reflected in the weight differences for carcass and cuts (absolute weights for breast, thigh, drumstick and wing). Therefore, only the differences in yield are 
SANTOS ET AL.

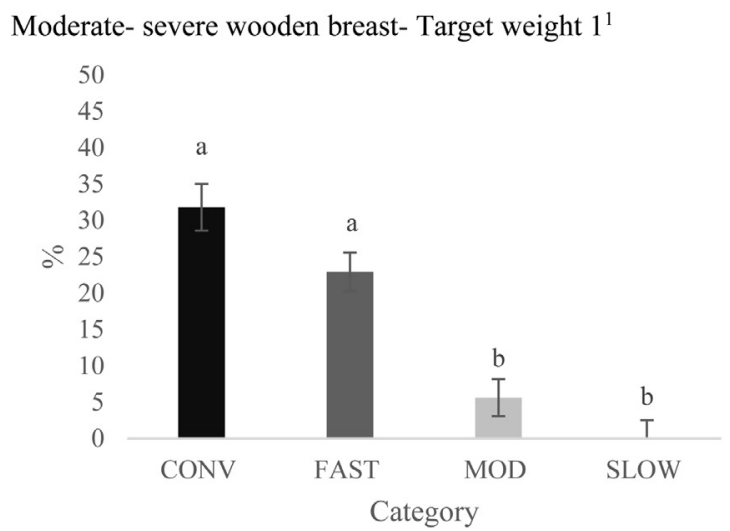

Moderate-severe wooden breast- Target weight $2^{2}$

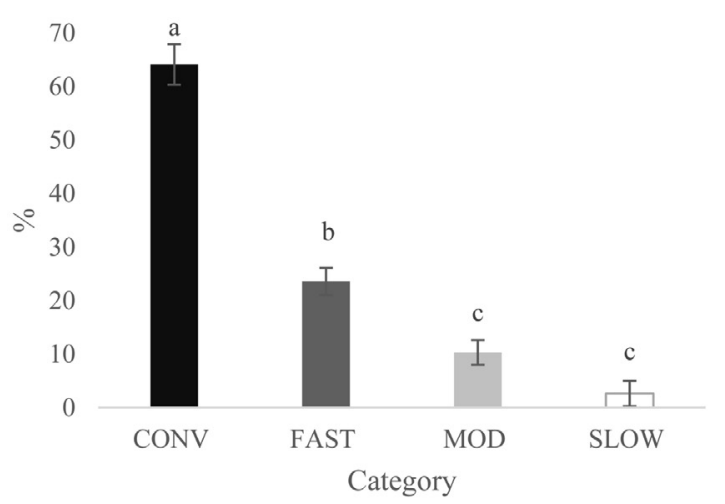

Moderate-severe white striping- Target weight $1^{3}$

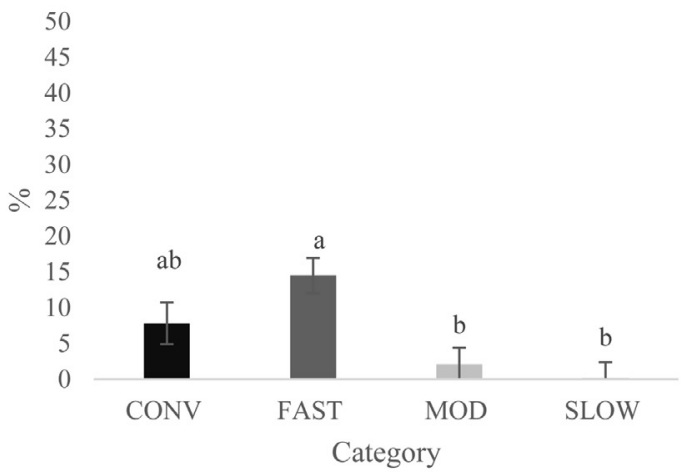

Moderate-severe white striping- Target weight $2^{4}$

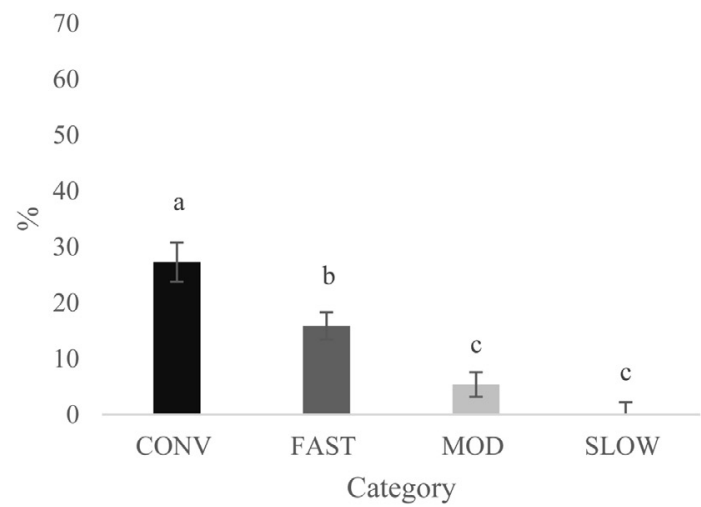

Figure 3. Effects of category on the total incidence of breast fillets presenting moderately severe (scores 2 or 3 ) wooden breast ${ }^{1,2}$ and white striping ${ }^{3,4}$ at Target Weights 1 and 2 (LS-means \pm SEM). At Target Weight 1, CONV and other categories were 34 and $48 \mathrm{~d}$ of age, respectively. At Target Weight 2, CONV and other categories were 48 and $62 \mathrm{~d}$, respectively.

${ }^{\mathrm{a}-\mathrm{c}}$ Different superscripts represent differences among categories $(P<0.05)$.

${ }^{1}$ Number of birds per category at target weight 1 : CONV: $\mathrm{n}=104$; FAST: $\mathrm{n}=156$; MOD: $\mathrm{n}=175 ;$ SLOW: $\mathrm{n}=173$.

${ }^{2}$ Number of birds per category at target weight 2 CONV: $\mathrm{n}=80 ;$ FAST: $\mathrm{n}=176 ;$ MOD: $\mathrm{n}=196 ;$ SLOW: $\mathrm{n}=198$.

${ }^{3}$ Number of birds per category at target weight 1 : CONV: $\mathrm{n}=91$; FAST: $\mathrm{n}=124$; MOD: $\mathrm{n}=159$; SLOW: $\mathrm{n}=125$.

${ }^{4}$ Number of birds per category at target weight 2 : CONV: $\mathrm{n}=64$ FAST: $\mathrm{n}=132$; MOD: $\mathrm{n}=171$; SLOW: $\mathrm{n}=162$.

discussed below. If not specified, differences described for yields are applicable for values relative to both the carcass and LW.

Effect of Category. Previous studies have found that increased BW is associated with increased incidence and severity of myopathies (Kuttappan et al., 2012a; Alnahhas et al., 2016). Therefore, the present study slaughtered birds at 2 time points (TW 1 and TW 2) based on their expected growth to allow comparisons at a similar BW for both conventional and slow growing strains. While birds were expected to reach approximately 2.1 and $3.2 \mathrm{~kg} \mathrm{BW}$, at TW 1 and TW 2 respectively, there were strain differences in BW at both TWs due to differences in ADG (43.6 to $68.7 \mathrm{~g} / \mathrm{d}$ ).

At TW 1, MOD and FAST were heavier than CONV and SLOW strains, with SLOW being heavier than CONV. The lighter BW for SLOW strains was expected based on classification due to reduced growth rate $(\mathrm{ADG}<50 \mathrm{~g} / \mathrm{d})$. However, CONV strains were lighter than the expected target weight of $2.1 \mathrm{~kg}$ due to project logistics which necessitated an early processing date $(\sim 2$ $\mathrm{d}$ before reaching $2.1 \mathrm{~kg} \mathrm{BW}$ ). The lower than expected BW at slaughter age for CONV birds may have been due to feeding an identical diet to all the birds in the study, which was formulated for slower growth. A pilot study (Santos et al., 2018) found this same diet produced lower BW vs. birds fed a standard, conventional diet. However, at TW 2, CONV had a similar BW compared to MOD and FAST strains, while SLOW strains were still lighter.

The lower BW for CONV and SLOW strains at TW 1 resulted in lighter carcass, breast, thigh, drumstick, and wing weights compared to FAST and MOD strains. While BW and carcass weights for CONV birds did not differ from those of MOD and FAST strains at TW 2, CONV birds had greater breast weights compared to other categories. Regardless, at both TWs, higher growth rate resulted in greater breast yield and lower thigh, drumstick and wing yields. These differences among categories of strains suggest that genetic 
Moderate-severe wooden breast- Target weight $1^{1}$

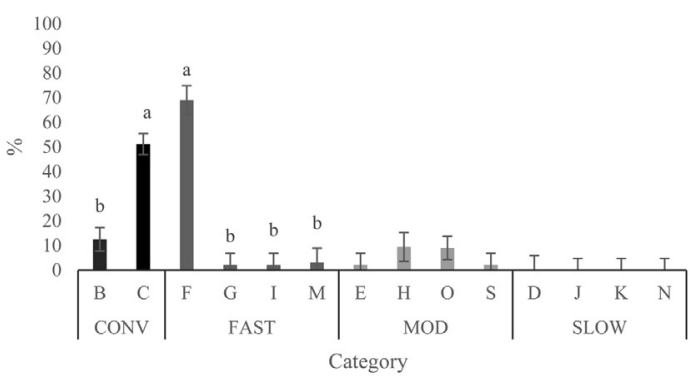

Moderate-severe wooden breast- Target weight $2^{2}$
Moderate-severe white striping- Target weight $1^{3}$

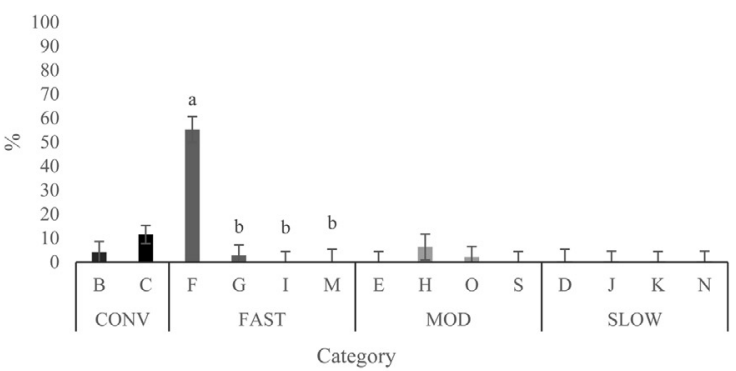

Moderate-severe white striping- Target weight $2^{4}$
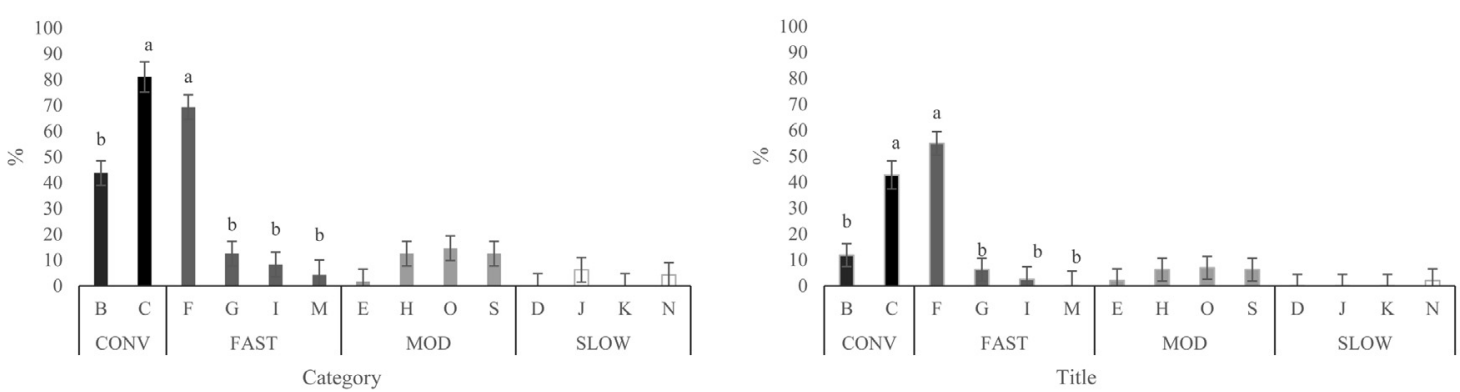

Figure 4. Effects of strains (within category) on the total incidence of breast fillets presenting moderately severe (scores 2 or 3 ) wooden breast ${ }^{1,2}$ and white striping ${ }^{3,4}$ at Target Weights 1 and 2 (LS-means \pm SEM). At Target Weight 1 , CONV and other categories were 34 and $48 \mathrm{~d}$ of age, respectively. At Target Weight $2, \mathrm{CONV}$ and other categories were 48 and $62 \mathrm{~d}$, respectively.

${ }^{\mathrm{a}-\mathrm{b}}$ Different superscripts within the same category represent differences among strains $(P<0.05)$.

${ }^{1}$ Number of birds per strain at target weight $1: \mathrm{B}: \mathrm{n}=52, \mathrm{C}: \mathrm{n}=52, \mathrm{~F}: \mathrm{n}=30, \mathrm{G}: \mathrm{n}=47, \mathrm{I}: \mathrm{n}=47, \mathrm{M}: \mathrm{n}=32, \mathrm{E}: \mathrm{n}=48, \mathrm{H}: \mathrm{n}=32, \mathrm{O}: \mathrm{n}=47, \mathrm{~S}$ : $\mathrm{n}=48, \mathrm{D}: \mathrm{n}=32, \mathrm{~J}: \mathrm{n}=47, \mathrm{~K}: \mathrm{n}=47, \mathrm{~N}: \mathrm{n}=47$.

${ }^{2}$ Number of birds per strain at target weight $2: \mathrm{B}: \mathrm{n}=48, \mathrm{C}: \mathrm{n}=32, \mathrm{~F}: \mathrm{n}=52, \mathrm{G}: \mathrm{n}=48, \mathrm{I}: \mathrm{n}=47, \mathrm{M}: \mathrm{n}=29, \mathrm{E}: \mathrm{n}=48, \mathrm{H}: \mathrm{n}=52, \mathrm{O}: \mathrm{n}=48, \mathrm{~S}$ : $\mathrm{n}=48, \mathrm{D}: \mathrm{n}=55, \mathrm{~J}: \mathrm{n}=48, \mathrm{~K}: \mathrm{n}=47, \mathrm{~N}: \mathrm{n}=48$.

${ }^{3}$ Number of birds per strain at target weight $1: \mathrm{B}: \mathrm{n}=45, \mathrm{C}: \mathrm{n}=46, \mathrm{~F}: \mathrm{n}=25, \mathrm{G}: \mathrm{n}=39, \mathrm{I}: \mathrm{n}=39, \mathrm{M}: \mathrm{n}=21, \mathrm{E}: \mathrm{n}=47, \mathrm{H}: \mathrm{n}=24, \mathrm{O}: \mathrm{n}=44, \mathrm{~S}$ : $\mathrm{n}=44, \mathrm{D}: \mathrm{n}=26, \mathrm{~J}: \mathrm{n}=28, \mathrm{~K}: \mathrm{n}=39, \mathrm{~N}: \mathrm{n}=32$.

${ }^{4}$ Number of birds per strain at target weight $2: \mathrm{B}: \mathrm{n}=36, \mathrm{C}: \mathrm{n}=28, \mathrm{~F}: \mathrm{n}=42, \mathrm{G}: \mathrm{n}=41, \mathrm{I}: \mathrm{n}=31, \mathrm{M}: \mathrm{n}=18, \mathrm{E}: \mathrm{n}=40, \mathrm{H}: \mathrm{n}=48, \mathrm{O}: \mathrm{n}=44, \mathrm{~S}$ : $\mathrm{n}=39, \mathrm{D}: \mathrm{n}=45, \mathrm{~J}: \mathrm{n}=37, \mathrm{~K}: \mathrm{n}=44, \mathrm{~N}: \mathrm{n}=36$.

selection influences not only growth rate but also carcass parts and processing yields. This is in agreement with Fanatico et al. (2008) and Singh et al. (2021), in which a fast-growing strain of broiler chicken had greater breast yield, yet lower wing and leg yields compared to a slower-growing strain. Selection for greater breast yield in fast-growing strains of broiler chickens is mainly due to the preference for and greater cost of this portion of the carcass in Western countries (Barbut, 2019).

We expected to find differences among strains with different growth rates in breast and carcass yields. Havenstein and colleagues (2003b) found greater breast and carcass yields in a modern (from 2001) strain of broiler chickens compared to an unselected (from 1957) strain. Despite differences in growth rates and carcass composition among categories in the present study, CONV strains had similar carcass yield compared to FAST and MOD, whereas SLOW had the lowest carcass yield at both TWs. These results indicate that selection for carcass yield has been successful in slower-growing strains with ADG $>50 \mathrm{~g} / \mathrm{d}$, despite their reduced efficiency and increased time to reach the market weight compared to CONV birds (Torrey et al., 2021). Greater carcass yields for conventional and some slower-growing strains can be attributed to a shift from consumption of the whole carcass to cut-up portions, with selection for maximum yield for main carcass parts and edible components (e.g., leg and breast) and minimal offal yield (e.g., head, neck, viscera, and giblets) (Brake et al., 1993; Petracci et al., 2015).

Effect of Strain. While strains were categorized based on their ADG to aid analyses, we found differences among strains within each category in carcass traits and composition. Some of these differences persisted as the birds aged, however others were age-dependent and were not consistent as the birds grew. Changes in carcass yield and composition with age have been reported in both conventional and slower-growing strains (Brake et al., 1993; Havenstein et al., 1994; Young et al., 2001). The differences found within categories suggest that despite similar growth and efficiency, strains from the same category may have undergone distinct selection criteria that resulted in differences for carcass traits and yield. Differences in yield from broiler chickens selected for similar growth performance have been observed in other studies. López et al. (2011) reported similar LW at d 42, yet differences in breast and carcass yield in 2 strains selected for distinct emphasis on yield maximization. Mehaffey et al. (2006) also found differences in breast yield among 5 commercial genotypes of broiler chickens despite their similar LW at 7 wk. 


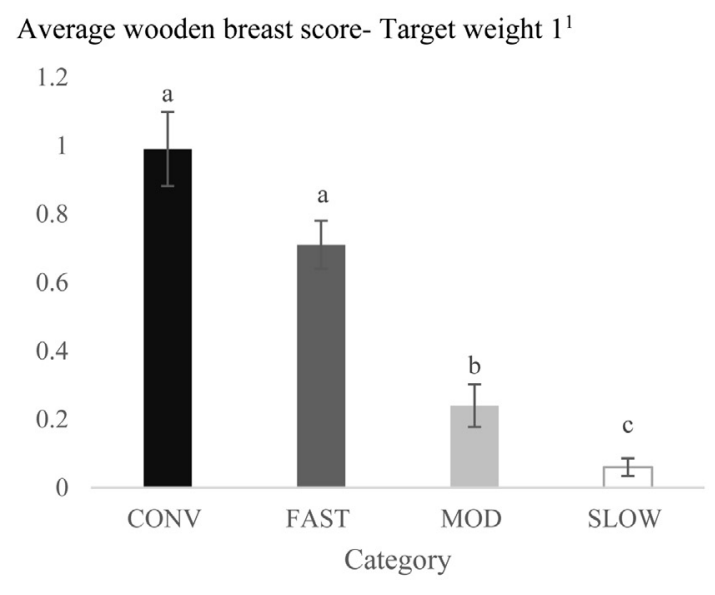

Average wooden breast score- Target weight $2^{2}$

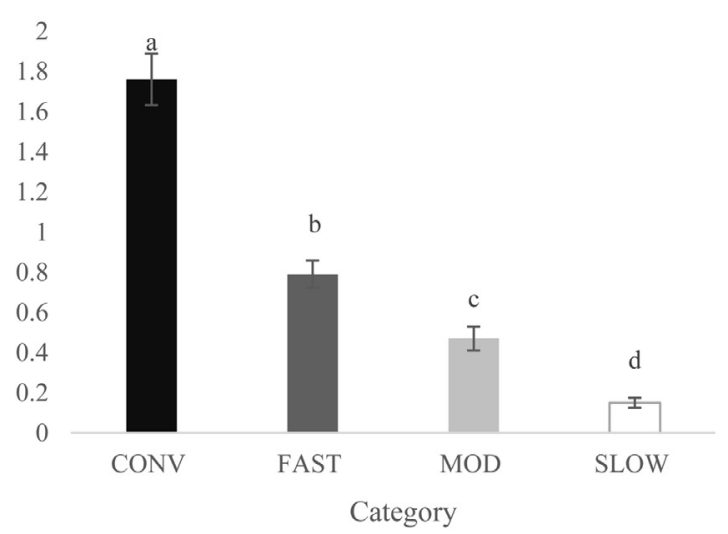

Average white striping score- Target weight $1^{3}$

1.2

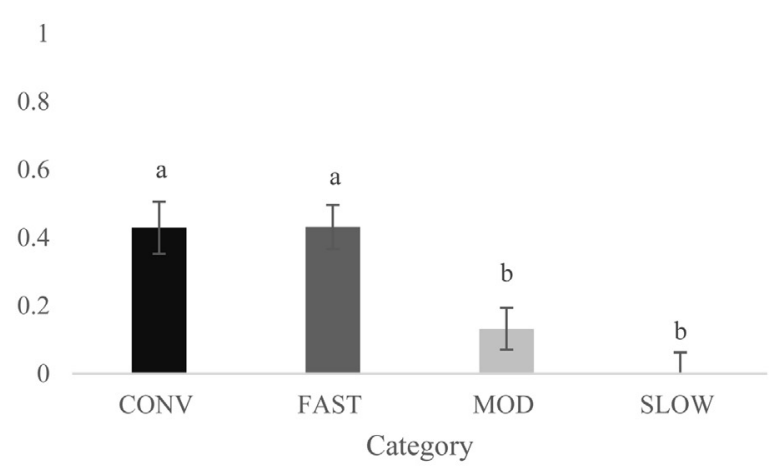

Average white striping score- Target weight $2^{4}$

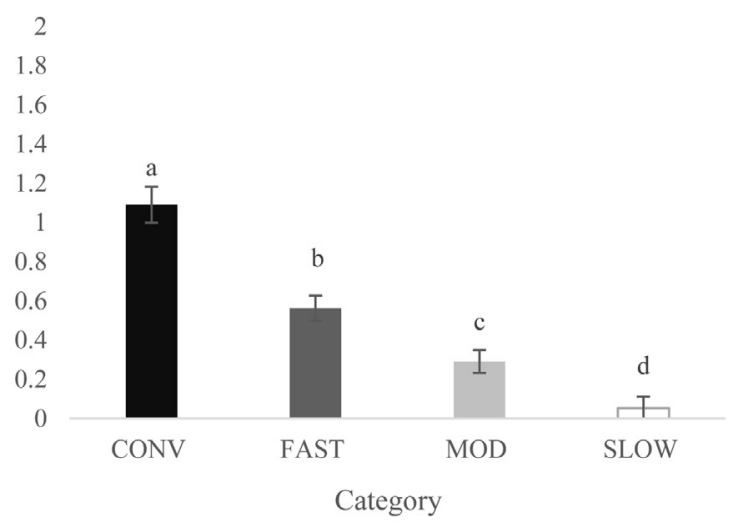

Figure 5. Effects of category on average of wooden breast ${ }^{1,2}$ and white striping ${ }^{3,4}$ scores at Target Weights 1 and 2 (LS-means \pm SEM). At Target Weight 1, CONV and other categories were 34 and $48 \mathrm{~d}$ of age, respectively. At Target Weight 2, CONV and other categories were 48 and $62 \mathrm{~d}$, respectively.

${ }^{\text {a-d }}$ Different superscripts represent differences among categories $(P<0.05)$.

${ }^{1}$ Number of birds per category at target weight 1: CONV: $\mathrm{n}=104 ;$ FAST: $\mathrm{n}=156 ;$ MOD: $\mathrm{n}=175 ;$ SLOW: $\mathrm{n}=173$.

${ }^{2}$ Number of birds per category at target weight 2 CONV: $\mathrm{n}=80 ;$ FAST: $\mathrm{n}=176 ;$ MOD: $\mathrm{n}=196 ;$ SLOW: $\mathrm{n}=198$.

${ }^{3}$ Number of birds per category at target weight 1 : CONV: $\mathrm{n}=91$; FAST: $\mathrm{n}=124 ;$ MOD: $\mathrm{n}=159 ;$ SLOW: $\mathrm{n}=125$.

${ }^{4}$ Number of birds per category at target weight 2 : CONV: $\mathrm{n}=64$ FAST: $\mathrm{n}=132$; MOD: $\mathrm{n}=171$; SLOW: $\mathrm{n}=162$.

Effect of Sex. As expected, sex affected weights of all carcass components evaluated, with males being heavier than females irrespective of target weight. The effect of sex on BW and processing traits has been well-documented and is mainly attributed to differences in growth performance between male and female broiler chickens (Shim et al., 2012). Similarly, sex affected the yield of carcass components, with females having lower yields for carcass, drumsticks, and thighs, yet greater yields for breasts than males. However, breast yield was not affected by sex for CONV and MOD categories. The greater breast yield of females compared to males has been reported in previous studies in both fast and slower-growing strains (Havenstein et al., 2003b; López et al., 2011). In contrast, Hussein et al. (2019) reported similar breast yields in females and males for a fast-growing strain of broiler chicken, which corroborates our findings, suggesting uniformity and selection for maximization of breast yield in both sexes. In general, the effects of sex on carcass yield and composition in the present study are in agreement with results in past studies evaluating different strains of broiler chickens (Brake et al., 1993; Young et al., 2001; López et al., 2011; Shim et al., 2012).

\section{Incidence and Severity of Myopathies}

Effect of Category. Similar to carcass traits, myopathies were influenced by category, with CONV birds having greater incidence, average scores, and severity for WB and WS than the remaining categories, especially at TW 2. These results are in agreement with those reported by Dixon (2020), who found a greater incidence of WB and WS in fast-growing strains compared to slower-growing birds. Even though the presence of these myopathies has not been thoroughly investigated in slower-growing birds, the association between accelerated growth rate and greater incidence of muscle abnormalities has been demonstrated in fast-growing 

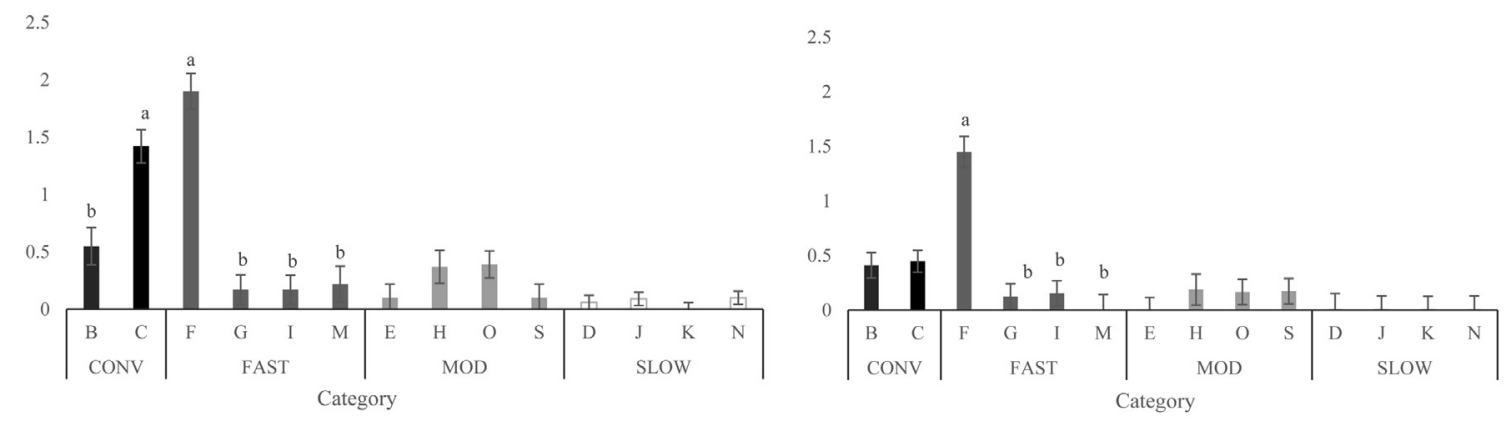

Average wooden breast score- Target weight $2^{2}$

Average white striping score- Target weight $2^{4}$
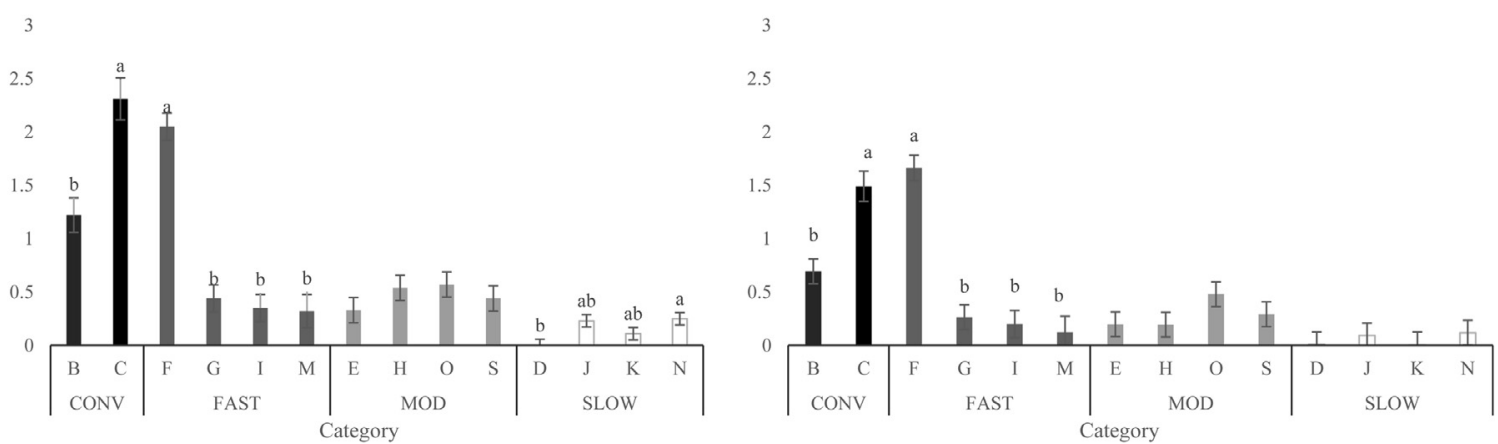

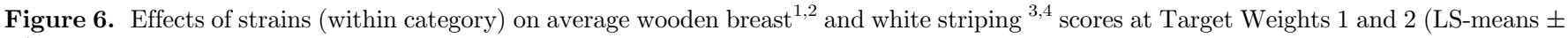
SEM). At Target Weight $1, \mathrm{CONV}$ and other categories were 34 and $48 \mathrm{~d}$ of age, respectively. At Target Weight 2 , CONV and other categories were 48 and $62 \mathrm{~d}$, respectively.

a-b Different superscripts within the same category represent differences among strains $(P<0.05)$.

${ }^{1}$ Number of birds per strain at target weight $1: \mathrm{B}: \mathrm{n}=52, \mathrm{C}: \mathrm{n}=52, \mathrm{~F}: \mathrm{n}=30, \mathrm{G}: \mathrm{n}=47, \mathrm{I}: \mathrm{n}=47, \mathrm{M}: \mathrm{n}=32, \mathrm{E}: \mathrm{n}=48, \mathrm{H}: \mathrm{n}=32, \mathrm{O}: \mathrm{n}=47, \mathrm{~S}$ : $\mathrm{n}=48, \mathrm{D}: \mathrm{n}=32, \mathrm{~J}: \mathrm{n}=47, \mathrm{~K}: \mathrm{n}=47, \mathrm{~N}: \mathrm{n}=47$.

${ }^{2}$ Number of birds per strain at target weight $2: \mathrm{B}: \mathrm{n}=48, \mathrm{C}: \mathrm{n}=32, \mathrm{~F}: \mathrm{n}=52, \mathrm{G}: \mathrm{n}=48, \mathrm{I}: \mathrm{n}=47, \mathrm{M}: \mathrm{n}=29, \mathrm{E}: \mathrm{n}=48, \mathrm{H}: \mathrm{n}=52, \mathrm{O}: \mathrm{n}=48, \mathrm{~S}$ : $\mathrm{n}=48, \mathrm{D}: \mathrm{n}=55, \mathrm{~J}: \mathrm{n}=48, \mathrm{~K}: \mathrm{n}=47, \mathrm{~N}: \mathrm{n}=48$.

${ }^{3}$ Number of birds per strain at target weight $1: \mathrm{B}: \mathrm{n}=45, \mathrm{C}: \mathrm{n}=46, \mathrm{~F}: \mathrm{n}=25, \mathrm{G}: \mathrm{n}=39, \mathrm{I}: \mathrm{n}=39, \mathrm{M}: \mathrm{n}=21, \mathrm{E}: \mathrm{n}=47, \mathrm{H}: \mathrm{n}=24, \mathrm{O}: \mathrm{n}=44, \mathrm{~S}$ : $\mathrm{n}=44, \mathrm{D}: \mathrm{n}=26, \mathrm{~J}: \mathrm{n}=28, \mathrm{~K}: \mathrm{n}=39, \mathrm{~N}: \mathrm{n}=32$.

${ }^{4}$ Number of birds per strain at target weight 2: B: $\mathrm{n}=36, \mathrm{C}: \mathrm{n}=28, \mathrm{~F}: \mathrm{n}=42, \mathrm{G}: \mathrm{n}=41, \mathrm{I}: \mathrm{n}=31, \mathrm{M}: \mathrm{n}=18, \mathrm{E}: \mathrm{n}=40, \mathrm{H}: \mathrm{n}=48, \mathrm{O}: \mathrm{n}=44, \mathrm{~S}$ : $\mathrm{n}=39, \mathrm{D}: \mathrm{n}=45, \mathrm{~J}: \mathrm{n}=37, \mathrm{~K}: \mathrm{n}=44, \mathrm{~N}: \mathrm{n}=36$.

Table 6. Spearman correlation coefficients $\left(\mathrm{r}_{\mathrm{s}}\right)$ between total incidence of myopathies and carcass parts and yield (as hatched broiler chickens) with the respective $P$-values in each category.

\begin{tabular}{|c|c|c|c|c|c|c|c|c|c|}
\hline \multirow{2}{*}{ Variable } & \multirow{2}{*}{$\begin{array}{l}\text { Coef. of correlation } \\
\text { and } P \text {-value }\end{array}$} & \multicolumn{2}{|c|}{ Conventional } & \multicolumn{2}{|c|}{ Fast } & \multicolumn{2}{|c|}{ Mod } & \multicolumn{2}{|c|}{ Slow } \\
\hline & & $\%$ of $\mathrm{WB}^{1}$ & $\%$ of $\mathrm{WS}^{2}$ & $\%$ of $\mathrm{WB}^{1}$ & $\%$ of $\mathrm{WS}^{2}$ & $\%$ of $\mathrm{WB}^{1}$ & $\%$ of $\mathrm{WS}^{2}$ & $\%$ of $\mathrm{WB}^{1}$ & $\%$ of $\mathrm{WS}^{2}$ \\
\hline \multirow[t]{2}{*}{ Live weight } & $\mathrm{r}_{\mathrm{s}}$ & 0.482 & 0.505 & 0.309 & 0.291 & 0.535 & 0.404 & 0.285 & 0.275 \\
\hline & $P$ & 0.003 & 0.002 & 0.006 & 0.010 & $<0.001$ & $<0.001$ & 0.008 & 0.001 \\
\hline \multirow{2}{*}{ Carcass yield } & $\mathrm{r}_{\mathrm{s}}$ & 0.546 & 0.369 & 0.605 & 0.719 & 0.417 & 0.478 & 0.233 & 0.279 \\
\hline & $P$ & 0.001 & 0.028 & $<0.001$ & $<0.001$ & $<0.001$ & $<0.001$ & 0.030 & 0.009 \\
\hline \multirow[t]{2}{*}{ Breast yield } & $\mathrm{r}_{\mathrm{s}}$ & 0.450 & 0.431 & 0.589 & 0.596 & 0.462 & 0.236 & 0.338 & 0.265 \\
\hline & $\stackrel{\vec{P}}{P}$ & 0.007 & 0.009 & $<0.001$ & $<0.001$ & $<0.001$ & 0.012 & 0.001 & 0.013 \\
\hline \multirow[t]{2}{*}{ Thigh yield } & $\mathrm{r}_{\mathrm{S}}$ & -0.055 & -0.068 & -0.303 & -0.188 & -0.094 & 0.012 & -0.095 & -0.077 \\
\hline & $P$ & 0.752 & 0.697 & 0.007 & 0.101 & 0.368 & 0.921 & 0.382 & 0.476 \\
\hline \multirow[t]{2}{*}{ Drumstick yield } & $\mathrm{r}_{\mathrm{s}}$ & -0.042 & -0.385 & -0.282 & -0.338 & -0.025 & 0.055 & -0.164 & -0.106 \\
\hline & $P$ & 0.809 & 0.002 & 0.012 & 0.003 & 0.850 & 0.606 & 0.128 & 0.330 \\
\hline \multirow[t]{2}{*}{ Wing yield } & $\mathrm{r}_{\mathrm{s}}$ & -0.265 & -0.167 & -0.511 & -0.502 & -0.377 & -0.282 & -0.223 & -0.168 \\
\hline & $P$ & 0.123 & 0.337 & $<0.001$ & $<0.001$ & 0.003 & 0.007 & 0.038 & 0.119 \\
\hline
\end{tabular}

Results were calculated on a pen basis.

${ }^{1}$ Number of birds per category: CONV: $\mathrm{n}=184 ;$ FAST: $\mathrm{n}=332$; MOD: $\mathrm{n}=371$; SLOW: $\mathrm{n}=371$.

${ }^{2}$ Number of birds per category: CONV: $\mathrm{n}=155$; FAST: $\mathrm{n}=256$; MOD: $\mathrm{n}=330$; SLOW: $\mathrm{n}=287$.

strains of broiler chickens (Kuttappan et al., 2012a; Lorenzi et al., 2014). These results suggest that muscle from fast-growing birds may not be accompanied by adequate supporting cells and tissues, leading to muscle damage and myopathies (Wilson et al., 1990;
Kuttappan et al., 2013a). Although the underpinning causes for development of WB and WS have yet to be elucidated, previous studies suggest that the development of breast muscle in modern strains of broiler chickens may be associated with insufficient supply of blood 

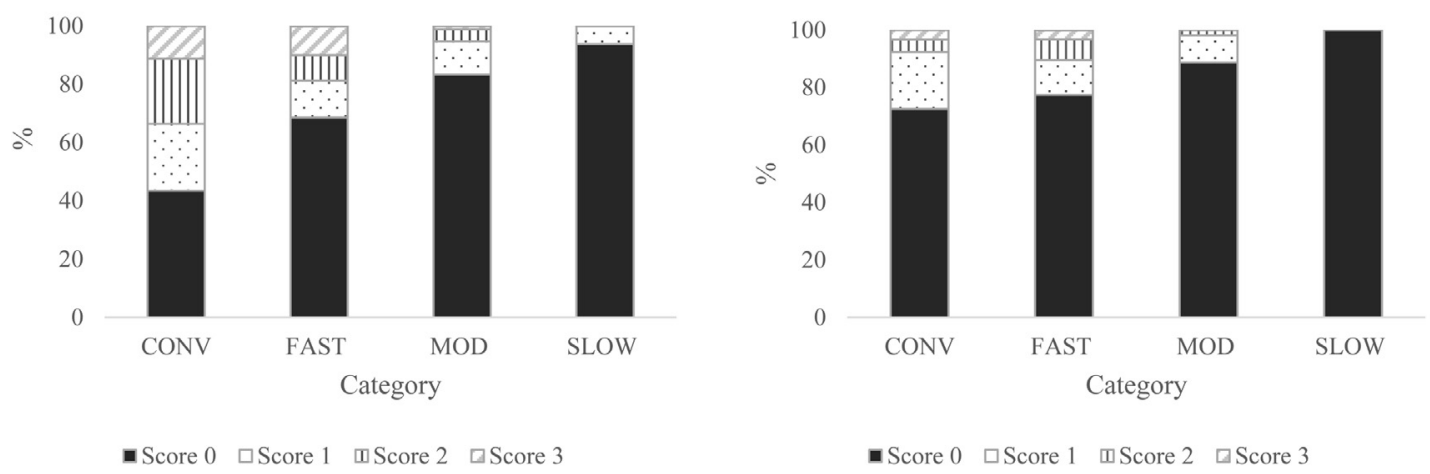

Wooden breast profile- Individual scores - Target weight $2^{2}$

White striping profile- Individual scores- Target weight $2^{4}$
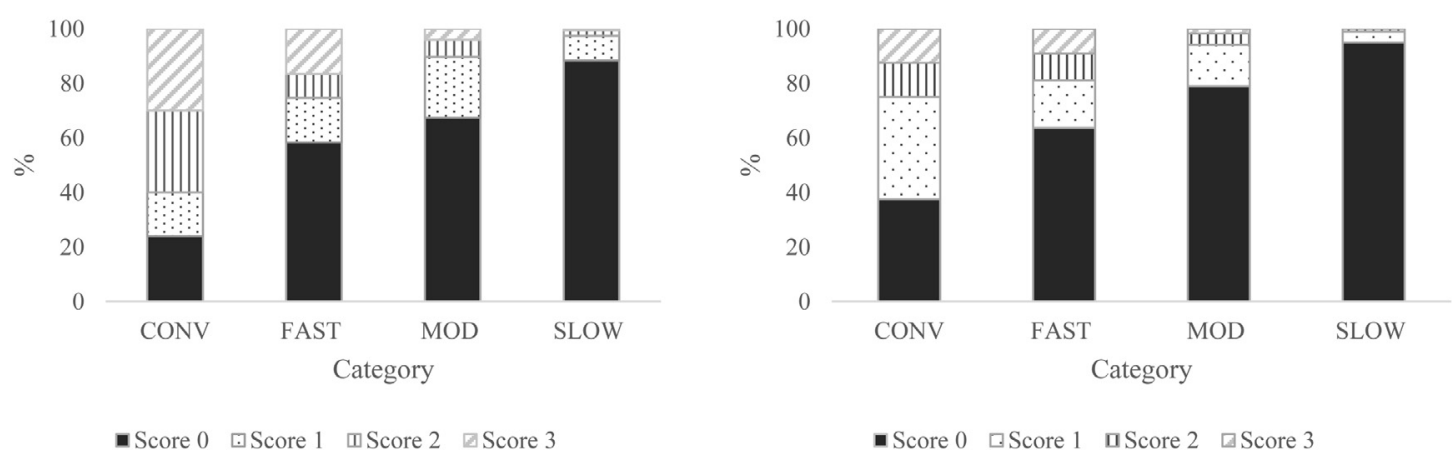

Figure 7. Wooden breast ${ }^{1,2}$ and white striping ${ }^{3,4}$ profile in different categories of broiler chickens at Target Weights 1 and 2 . Only descriptive statistics are provided for this variable. At Target Weight 1, CONV and other categories were 34 and $48 \mathrm{~d}$ of age, respectively. At Target Weight 2 , CONV and other categories were 48 and $62 \mathrm{~d}$, respectively.

${ }^{1}$ Number of birds per category at target weight 1 : CONV $\mathrm{n}=104 ;$ FAST $\mathrm{n}=156 ;$ MOD $\mathrm{n}=175 ;$ SLOW $\mathrm{n}=173$.

${ }^{2}$ Number of birds per category at target weight 2 : CONV $\mathrm{n}=80 ;$ FAST $\mathrm{n}=176 ;$ MOD $\mathrm{n}=196 ;$ SLOW $\mathrm{n}=198$.

${ }^{3}$ Number of birds per category at target weight 1 : CONV $\mathrm{n}=91 ; \mathrm{FAST} \mathrm{n}=124 ; \mathrm{MOD} \mathrm{n}=159 ; \mathrm{SLOW} \mathrm{n}=125$.

${ }^{4}$ Number of birds per category at target weight 2 : CONV $\mathrm{n}=64 ;$ FAST $\mathrm{n}=132 ; \mathrm{MOD} \mathrm{n}=171 ; \mathrm{SLOW} \mathrm{n}=162$.

and oxygen to the muscle (Sihvo et al., 2018; Petracci et al., 2019). Since muscle fiber formation in chicks is completed at hatch, posthatch muscle growth is attributed to the enlargement of myofibers (Clark and Velleman, 2017). Fast-growing strains of broiler chickens have greater myofiber diameters in the Pectoralis major compared to laying hens (MacRae et al., 2006). Selection for increased breast size and yield has been associated with increase in breast thickness in the cranial region of the breast, which is speculated to have larger myofibers than the caudal region (Clark and Velleman, 2017). This enlargement of muscle fibers posthatch has been linked to poor circulation due to the reduced space available for capillaries and blood supply, leading to tissue hypoxia and reduced transportation of nutrients to the muscle (Sihvo et al., 2018; Petracci et al., 2019). These effects increase the potential for muscle fiber damage and metabolic stress (MacRae et al., 2006; Clark and Velleman, 2017; Sihvo et al., 2018). In fact, breast muscle tissues from WB affected birds, which also commonly exhibit WS, often have increased levels of biomarkers associated with oxidative stress and muscle degeneration (Abasht et al.,
2016). In our study, we found that CONV birds had the greatest plasma concentrations of aspartate transaminase (AST), lactate dehydrogenase $(\mathrm{LDH})$ and creatine kinase (CK) compared to the other categories (unpublished data). However, strain F (FAST) had the greatest level of these enzymes among FAST birds, exhibiting values as high as CONV birds, with $\mathrm{AST}$, LDH, and CK being 1.75 to $1.85,2$ to 2.5 and 3.9 to 5.8 fold greater than the remaining FAST birds, respectively (unpublished data). CONV strains and strain $\mathrm{F}$ also had the greatest breast yield and incidence of myopathies among all strains. While we have not yet analyzed the correlations between these enzymes and carcass traits, these findings are in line with Kuttappan et al. (2013b) who found differences in serum biochemical profile between normal and severe WS affected chickens, with the latter exhibiting greater levels of AST, LDH, and CK. In agreement with these findings, a study conducted as part of our large project compared the plasma attributes of one conventional (B) and 4 slower-growing strains (D, $\mathrm{E}, \mathrm{H}$, and $\mathrm{M})$ at $48 \mathrm{~d}$. The authors reported greater plasma concentrations of $\mathrm{AST}, \mathrm{LDH}$, and $\mathrm{CK}$ in strain $\mathrm{B}$ compared to the remaining slower-growing strains 
tested (Mohammadigheisar et al., 2020). Elevated concentrations could be due to muscle damage, causing disruption of the sarcolemma and leakage of such enzymes into the plasma or serum (Kuttappan et al., 2013b). Besides the impacts of WB and WS on meat quality, consumer acceptance, and biochemical profile, recent studies have suggested these myopathies may also compromise the behavior, health, and welfare of broiler chickens. In fact, a study conducted to investigate the etiology of WB disorder found that some birds showing this abnormality were unable to right themselves when accidentally falling on their back (dorsal recumbency) (Papah et al., 2017). In addition, birds affected by WB appeared reluctant to general movement. The authors emphasized that WB affected birds exhibited tissue pathology that has been associated with painful conditions in humans. Even though pain assessment was not conducted in that study, the researchers suggested that WB disorder may have welfare implications in broiler chickens (Papah et al., 2017). In another study, Gall et al. (2019) reported that WB was not only associated with dorsal recumbency, but also with pulmonary disease and mortality. In fact, $71 \%$ of the late mortality (last $16 \mathrm{~d}$ of a rearing period of $56 \mathrm{~d}$ ) were heavy males, with evaluation of gross lesions revealing that $68 \%$ of the dead birds (culls and found dead) exhibited WB and concurrent pulmonary disease. The authors concluded that besides the well-known adverse effects of WB on meat quality, this disorder also brings welfare concerns due to the inability of some of the affected birds to stand after falling onto their backs, which can lead to respiratory distress and even death if the birds are not righted quickly. Similarly, Norring et al. (2018) reported behavioral differences, with less movements while lying down and poorer gait scores at different ages in WB-affected birds as compared to non-affected counterparts, indicating impaired walking ability for the former group. The authors concluded that the occurrence of lameness observed in broiler chickens may be partially associated with the incidence of WB. However, the heavier BW and greater breast yield for WB-affected birds may have contributed to both the occurrence of the WB myopathy and poorer gait score (Norring et al., 2018). Even though the walking ability was not investigated by De Almeida Mallmann et al. (2019), they observed a reduced femur diameter and calcium, and phosphorus percentages, yet greater breast weight and fillet thickness in WB-affected birds compared to unaffected birds, suggesting a possible relationship between WB disorder and bone mineralization. In addition, elevated levels of metabolites that are often associated with inflammation, tissue injury, and pain have been found in breast muscle tissue samples from WB-affected birds (Abasht et al., 2016). A recent study suggests similarities between type 2 diabetes and WB, indicating a possible dysregulation of lipid and glucose metabolism in WB cases (Lake and Abasht, 2020). Wooden breast-affected birds have also shown signs of gas disturbance in a study by Lake et al. (2020), who reported higher partial pressure of $\mathrm{CO}_{2}$ and total $\mathrm{CO}_{2}$, yet lower $\mathrm{pH}$, partial pressure of $\mathrm{O}_{2}$, and $\mathrm{O}_{2}$ saturation in blood samples of males exhibiting WB compared to unaffected birds. The authors suggest that WB-affected birds may have respiratory acidosis as indicated by the low $\mathrm{pH}$ and high partial pressure of $\mathrm{CO}_{2}$. Respiratory acidosis may be attributed to the increase in $\mathrm{CO}_{2}$ production, insufficient respiratory gas exchange (cardiopulmonary insufficiency), or both, suggesting an elevated metabolic rate that is not be properly supported by adequate systems. Other researchers reported that birds with any degree of WB myopathy were incapable of fully lifting their wings, which has been suggested as a clinical symptom and potential method for detection of WB in live birds (Kawasaki et al., 2016). Although not yet investigated, the inability to fully lift the wings, possibly because of reduced extensibility of the degenerated muscle as suggested by Kawasaki et al. (2016), could potentially prevent or reduce behaviors the birds may be motivated to perform, such as wing flapping. The inability of some WB affected birds to right themselves from dorsal recumbency has been speculated to be attributed to the damage of the Pectoralis major muscle, preventing the effective use of wing-assisted movements needed to turn the birds back onto their legs (Gall et al., 2019). All together, these findings suggest that the modern myopathies commonly reported in fast-growing strains of broiler chickens may have significant welfare implications and should be further investigated.

At the heavier processing weight, the incidence of WS (53 to $80 \%$ ) found in the present study for CONV strains was similar to those reported by Dixon (2020) for birds at $42 \mathrm{~d}(63$ to $78 \%)$ but lower than other recent studies that reported almost all $(>90 \%)$ breast fillets from fastgrowing strains exhibited some degree of WS (Kuttappan et al., 2017; Chen et al., 2019). The percentages of WB-affected breasts in CONV birds in the present study at TW 1 (36 to $70 \%$ ) and TW 2 (70 to 84\%) were greater than values found in some previous studies (Trocino et al., 2015; Gratta et al., 2019; Dixon, 2020), but similar to those reported elsewhere (Cruz et al., 2017; Kuttappan et al., 2017; Bodle et al., 2018). The discrepancy in the incidence of myopathies may be due to subjective evaluation (palpation and visual) of myopathies. In addition, genetics along with non-genetic factors (e.g., diet, incubation, age, growth rate) also influence carcass yield, composition, and incidence of WB and WS in broiler chickens (Kuttappan et al., 2012b, 2013a, 2017; Clark et al., 2017; Cruz et al., 2017).

The birds used in the present study were incubated and reared under similar environmental conditions, with a standardized stocking density and no outdoor access. A controlled and similar environment allowed us to investigate differences among strains under standardized housing and management. However, different strains may have different responses to the conditions provided. Therefore, the incubation and environmental conditions in the present study may have affected the strains differently, with some strains performing better than others as a result. In fact, ideal incubation conditions may vary according to many factors, including the breeder 
genetics, and age, yolk size and egg composition, eggshell properties, length, and temperature of storage (reviewed in Oviedo-Rondón et al., 2020). There is evidence that modified or suboptimal incubation conditions may affect the incidence of myopathies in poultry (OviedoRondón et al., 2020). A recent study by Nyuiadzi et al. (2020) demonstrated that chickens from eggs exposed to a short, cold temperature $\left(15^{\circ} \mathrm{C}\right.$ for 30 min) during the last stages of incubation, had slightly lower incidence of WS compared to the control-incubated group when birds were reared in optimal (control) temperatures. However, when exposed to early cold rearing temperatures, the incidence of WS in those males from the cold-incubated group was higher than males from the control-rearing group, suggesting a possible interaction between incubation and posthatch conditions on the incidence of myopathies. In addition, all birds were fed the same 3-phase diet that may not be suitable to optimize the growth and productive performance for conventional birds, but enabled the comparisons under standardized conditions The influence of diet on the incidence of myopathies has been reported in earlier studies (Cruz et al., 2017; Livingston et al., 2019; Sachs et al., 2019). Although most of studies only tested fast-growing strains, the standard diet used in our study may have affected slow and fast-growing strains differently based on their specific nutrient requirements. Furthermore, the diet formulated for slower-growth in our study resulted in a reduction in BW in CONV birds, but only at the end of the production cycle (42 d) as demonstrated in a study previously conducted by our research team (Santos et al., 2018). Due to the positive correlation between BW and the incidence of myopathies (Kuttappan et al., 2013b; Alnahhas et al., 2016; Petracci et al., 2019), an effect of diet would be expected as a result of the reduced BW in CONV birds. However, CONV birds reached the expected BW of $3.2 \mathrm{~kg}$ at TW 2 , suggesting that the impacts of diet on BW might have occurred in earlier stages of growth. Interestingly, Torrey et al. (2021) reported some differences in ADG to TW 1 in some strains compared to the breeder's expected growth rate, suggesting that strains may have responded differently to the diets and rearing conditions, which may have influenced the results observed in the present study. Therefore, considering the heterogeneous group of birds evaluated, the conditions the birds were incubated, reared, and fed may have affected the incidence and severity of myopathies observed among strains. However, considering the number of strains investigated in this study, optimizing diet, incubation, and rearing conditions for each strain was not feasible in our research facility.

Despite the contribution of growth rate to the incidence of muscle disorders, an increase in breast yield was also associated with greater incidences of myopathies. In contrast, as drumstick, thigh, and wing yield increased, the presence of WB and WS decreased. Correlation analysis supported these findings, with breast yield positively correlated and the percentage yield of drumstick, thigh, and wing negatively correlated with the myopathies in some categories of strains. These findings are in agreement with many studies that found increased growth rate and greater breast meat yield were critical crucial factors in the development of muscle disorders in modern strains of broiler chickens (Kuttappan et al., 2012a, 2013a, 2017; Petracci et al., 2013; Lorenzi et al., 2014; Mudalal et al., 2015; Alnahhas et al., 2016). However, the possibility of increasing breast muscle yield while reducing the genetic propensity to develop myopathies, has been reported in fast-growing birds as a result of a balanced breeding program (Bailey et al., 2015, 2020).

Lake et al. (2020) recently reported greater Pectoralis major in WB-affected birds, confirming the potential association between high breast yield and the development of myopathies, possibly due to a reduction in capillary density and overstretching of myofibers (Kuttappan et al., 2013c; Dalle Zotte et al., 2017). However, because WB lesions can be detected as early as 1 wk of age (Papah et al., 2017), it was suggested that the hypothesis that WB is caused by overstretching of myofibers may not accurately and fully explain the onset of the disorder (Lake et al., 2020). Despite the potential contribution of breast yield on the incidence of $\mathrm{WB}$ and WS, other alternative explanations for this relationship should not be discarded. As an example, recent studies suggest that breast muscle hypertrophy may be a symptom rather than the cause of myopathies, similar to the hypertrophy of organs (e.g., kidneys, heart, liver) observed in some diabetic complications in mammals (Lake et al., 2019; Lake and Abasht, 2020).

Besides the presence of WB and WS, the incidence of spaghetti meat, characterized by the loss of integrity and separation of muscle fiber bundles, has also been observed in broiler chickens, affecting up to $20 \%$ of the birds at processing age (Petracci et al., 2021). Although not investigated in this present study, the incidence of this disorder should be determined in future studies comparing slow and fast-growing strains of broiler chickens due to the negative effects of this myopathy on meat quality. Furthermore, due to the effects of WB and WS on meat quality, nutritional profile, histological traits, and gene expression (Mudalal et al., 2015; Velleman and Clark, 2015; Dalle Zotte et al., 2017), other studies should investigate these variables in strains selected for distinct growth rates to provide a better understanding of the changes associated with muscle disorders.

Effect of Strain. We found differences among strains within the same category, despite their similar production performance and LW at both processing ages. Strain C, within the CONV category and strain F, within the FAST category had a greater incidence and greater average scores for muscle disorders than other strains within their categories. The incidence and severity of myopathies in strain $\mathrm{F}$ were similar to those found in strain $\mathrm{C}$ and even greater than the values for strain $\mathrm{B}$, despite the slower growth rate for strain $\mathrm{F}$ compared to the CONV birds. These 2 strains also had the greatest breast yield among all the strains tested, suggesting that despite the irrefutable role of ADG on the incidence of 
muscle disorders, breast yield may also be a major contributor to the high incidence of WB and WS.

Other groups have investigated the incidence of myopathies in strains selected for similar growth rates but different breast yield. Even though this association was not consistently found (Trocino et al., 2015), selection for greater breast yield has been linked with greater incidence of myopathies even when growth rates are similar (Petracci et al., 2013; Lorenzi et al., 2014). In fact, a study conducted to determine the genetic parameters of WS found that this myopathy is more genetically correlated to the development of the breast muscle than to the increase in BW (Alnahhas et al., 2016). The association between high breast yield and the incidence of muscle disorders has been speculated to be the result of a mismatch between increased fiber size and inadequate capillary development, which can lead to insufficient oxygen and nutrients supplied to muscle cells and impaired removal of lactic acid from the muscle, resulting in muscle damage (Kuttappan et al., 2013a; Petracci et al., 2015; Chen et al., 2019). In fact, Hoving-Bolink et al. (2000) found that lower capillary density was associated with higher breast muscle yield but not with BW, suggesting that selection for increased percentage of breast muscle may lead to diminished oxygen supply to the breast muscle tissue and possibly detrimental effects on meat quality.

Effects of Sex, Target Weight, and Body Weight. Sex and target weight also influenced the incidence of muscle disorders; males and birds processed at TW 2 had the greatest values for WB and WS. Overall, females had higher breast yield than males, yet lower incidence of WB and WS compared to males. Both growth rate and breast yield have shown to influence the occurrence of myopathies in broiler chickens (Kuttappan et al., 2012a, 2017; Alnahhas et al., 2016). Therefore, the lower occurrence of breast fillets affected by myopathies in females might be a result of their lower BW, lower average daily gain, and lighter breast fillets compared to males. Other studies have suggested WB and WS are mainly affected by non-genetic factors (Bailey et al., 2015, 2020; Kuttappan et al., 2017). Interestingly, the effects of target weight and sex disappeared with the inclusion of $\mathrm{BW}$ in the statistical model, whereas the differences among categories and strains remained. Since males were heavier than females and birds processed at TW 2 were heavier than those processed at TW 1, the effects of sex and target weight on myopathies incidence are most likely due to the differences in BW. Similar findings were reported by Kuttappan et al. (2013a), who suggested that the greater percentage of breast fillets affected by WS in males may be the result of their heavier carcass weights and thicker breast fillets compared to females processed at a similar age. Alternatively, differences in gene expression between sexes may have contributed to the higher susceptibility of males to myopathies, as suggested by Brothers et al. (2019), who found almost 200 genes upregulated in males that may influence metabolic processes involved in the occurrence of WB disease. Despite the initial plan to process the birds at the same BW to allow comparisons between strains by weight, this was not possible due to the large strain differences in growth rate, availability of the processing plant, and logistics for the project. Since differences in BW may affect the percentage and severity of breast fillets affected by myopathies, this factor should be controlled for in future studies. However, because the effects of categories and strains remained even when the differences in BW were taken into account, genetics appears to play a crucial role for the incidence of muscle disorders in broiler chickens.

In conclusion, our results indicate that processing traits and the incidence and severity of WB and WS are affected by strain, primarily dependent on growth rates. CONV birds had lower thigh, drumstick, and wing yields, yet greater breast yield and percentage of breast fillets exhibiting muscle disorders compared to the other categories of strains. The greater incidence for WB and WS in strains selected for similar growth rates but greater breast yield suggests that increased breast meat development and yield may be the underpinning factor associated with muscle abnormalities in both fast and slower-growing strains. Further field studies should be conducted to investigate if the results obtained in our study under experimental conditions can be extrapolated to commercial poultry houses.

\section{ACKNOWLEDGMENTS}

This project was possible due to the financial support from Global Animal Partnership and the Canada First Research Excellence Fund. In-kind support was received from Ontario Agri-Food Innovation Alliance, the anonymous breeding companies and Protekta, Inc. We are grateful for the services offered by the Farm Fresh Poultry, ENS Poultry and Pullets Plus that enabled the transport and processing of birds. We appreciate all the technical support and help provided by Brian McDougall, Cheryl Campbell, Danielle Renwick, Judy Kendall, Linda Caston, Sam Leo and Xiaohui (Lucy) Du. This project could not have happened without the diligent help of our student assistants (in alphabetical order): Alan Abdulkadar, Breanna Jackson, Erin Ross, Kayley Teal, King (Stella) Hung, Jessica Woods, Leah Wellard, Madeleine Browne, Margaret Daoust, Megan Weckwerth, Melanie Felker, Narissa Leslie, Nyasha Mombeshora, Priyanka Thavaraja, Quinn Rausch, Siobhan Mellors and Veronica Cheng. Finally, the assistance of the Arkell Poultry Research Station staff was pivotal to this project's success. We thank Dave Vandenberg, Innes Wilson, Nancy Wedel, Vern Wideman, Heidi Naumann, Rick Hoiting and Danielle Watson for all their help.

This research was funded by the Global Animal Partnership, the Canada First Research Excellence Fund, Food from Thought, and Ontario Agri-Food Innovation Alliance. 


\section{DISCLOSURES}

All the authors reviewed the manuscript and approved the submission to Poultry Science, and confirmed that the manuscript has not been published and is not under consideration and review by another journal. We declare no conflict of interest on the publication of this manuscript.

\section{REFERENCES}

Abasht, B., M. F. Mutryn, R. D. Michalek, and W. R. Lee. 2016. Oxidative stress and metabolic perturbations in wooden breast disorder in chickens (AG Passi, Ed.). PLoS One 11:e0153750.

De Almeida Mallmann, B., E. M. Martin, K. S. Kim, N. L. Calderon-Apodaca, M. F. A. Baxter, J. D. Latorre, X. Hernandez-Velasco, L. Paasch-Martinez, C. M. Owens, S. Dridi, W. G. Bottje, E. S. Greene, and G. Tellez-Isaias. 2019. Evaluation of bone marrow adipose tissue and bone mineralization on broiler chickens affected by wooden breast myopathy. Front. Physiol. 10:674.

Alnahhas, N., C. Berri, M. Chabault, P. Chartrin, M. Boulay, M. C. Bourin, and E. Le Bihan-Duval. 2016. Genetic parameters of white striping in relation to body weight, carcass composition, and meat quality traits in two broiler lines divergently selected for the ultimate $\mathrm{pH}$ of the pectoralis major muscle. BMC Genet 17:61.

Bailey, R. A., E. Souza, and S. Avendano. 2020. Characterising the influence of genetics on breast muscle myopathies in broiler chickens. Front. Physiol. 11:1041.

Bailey, R. A., K. A. Watson, S. F. Bilgili, and S. Avendano. 2015. The genetic basis of pectoralis major myopathies in modern broiler chicken lines. Poult. Sci. 94:2870-2879.

Barbut, S. 2015. Global Perspective. Chapter 2. The Science of Poultry and Meat Processing University of Guelph. Guelph, Ontario, Canada.

Barbut, S. 2019. Recent myopathies in broiler's breast meat fillets. Worlds. Poult. Sci. J. 75:559-582.

Bodle, B. C., C. Alvarado, R. B. Shirley, Y. Mercier, and J. T. Lee. 2018. Evaluation of different dietary alterations in their ability to mitigate the incidence and severity of woody breast and white striping in commercial male broilers. Poult. Sci. 97:3298 3310 .

Bohrer, B. M., S. Chalupa-Krebzdak, L. M. Wang, S. Huang, and S. M. V. Mejia. 2018. Correlation of chicken breast (Pectoralis major) quality and sensory attributes with chicken thigh quality and sensory attributes. Meat Muscle Biol. 2 85-85.

Brake, J., G. B. Havenstein, S. E. Scheideler, P. R. Ferket, and D. V Rives. 1993. Relationship of sex, age, and body weight to broiler carcass yield and offal production 1. Poult. Sci. 72:11371145 .

Brothers, B., Z. Zhuo, M. B. Papah, and B. Abasht. 2019. RNA-seq analysis reveals spatial and sex differences in pectoralis major muscle of broiler chickens contributing to difference in susceptibility to wooden breast disease. Front. Physiol. 10:764.

Cai, K., W. Shao, X. Chen, Y. L. Campbell, M. N. Nair, S. P. Suman, C. M. Beach, M. C. Guyton, and M. W. Schilling. 2018. Meat quality traits and proteome profile of woody broiler breast (pectoralis major) meat. Poult. Sci. 97:337-346.

CCAC. Canadian Council on Animal Care guidelines on the care and use of farm animals in research, teaching and testing. (2009). Canadian Council on Animal Care in Science.

Che, S., S. Barbut, C. Wang, C. Fuchs, C. Varga, and D. Bienzle. 2020. Prevalence and risk factors associated with breast fillets myopathies (spaghetti meat, woody breast, and white striping) in broiler chickens from Ontario, Canada.. Poul. Sci. 99:62-63 (Abstr.).

Chen, L. R., M. M. Suyemoto, A. H. Sarsour, H. A. Cordova, E. O. Oviedo-Rondón, M. Wineland, H. J. Barnes, and L. B. Borst. 2019. Temporal characterization of wooden breast myopathy ("woody breast") severity and correlation with growth rate and lymphocytic phlebitis in three commercial broiler strains and a random-bred broiler strain. Avian Pathol. 48:319-328.
Clark, D. L., and S. G. Velleman. 2017. Physiology and reproduction: Spatial influence on breast muscle morphological structure, myofiber size, and gene expression associated with the wooden breast myopathy in broilers. Poult. Sci. 95:2930-2945.

Clark, D. L., K. G. Walter, and S. G. Velleman. 2017. Incubation temperature and time of hatch impact broiler muscle growth and morphology. Poult. Sci. 96:4085-4095.

Cruz, R. F. A., S. L. Vieira, L. Kindlein, M. Kipper, H. S. Cemin, and S. M. Rauber. 2017. Occurrence of white striping and wooden breast in broilers fed grower and finisher diets with increasing Lysine levels. Poult. Sci. 96:501-510.

Dalgaard, L. B., M. K. Rasmussen, H. C. Bertram, J. A. Jensen, H. S. Møller, M. D. Aaslyng, E. K. Hejbøl, J. R. Pedersen, D. Elsser-Gravesen, and J. F. Young. 2018. Classification of wooden breast myopathy in chicken pectoralis major by a standardised method and association with conventional quality assessments. Int. J. Food Sci. Technol. 53:1744-1752.

Dalle Zotte, A., G. Tasoniero, E. Puolanne, H. Remignon, M. Cecchinato, E. Catelli, and M. Cullere. 2017. Effect of "wooden breast" appearance on poultry meat quality, histological traits, and lesions characterization. Czech J. Anim. Sci. 62:51-57.

Dixon, L. M. 2020. Slow and steady wins the race: The behaviour and welfare of commercial faster growing broiler breeds compared to a commercial slower growing breed. PLoS One 15:e231006.

Fanatico, A. C., P. B. Pillai, P. Y. Hester, C. Falcone, J. A. Mench, C. M. Owens, and J. L. Emmert. 2008. Performance, livability, and carcass yield of slow- and fast-growing chicken genotypes fed low-nutrient or standard diets and raised indoors or with outdoor access. Poult. Sci. 87:1012-1021.

Ferreira, T. Z., L. Kindlein, J. J. Flees, L. K. Shortnacy, S. L. Vieira, V. P. Nascimento, K. J. Meloche, and J. D. Starkey. 2020. Characterization of Pectoralis major muscle satellite cell population heterogeneity, macrophage density, and collagen infiltration in broiler chickens affected by wooden breast. Front. Physiol. 11:1-11.

Food and Agriculture Organization of the United Nations. 2019. Accessed Oct. 2020. http://www.fao.org/faostat/en/\#data.

Gall, S., M. M. Suyemoto, H. M. L. Sather, A. R. Sharpton, H. J. Barnes, and L. B. Borst. 2019. Wooden breast in commercial broilers associated with mortality, dorsal recumbency, and pulmonary disease. Avian Dis. 63:514-519.

Gratta, F., M. Birolo, R. Sacchetto, G. Radaelli, G. Xiccato, C. Ballarin, D. Bertotto, A. Piccirillo, M. Petracci, L. Maertens, and A. Trocino. 2019. Effect of feed restriction timing on live performance, breast myopathy occurrence, and muscle fiber degeneration in 2 broiler chicken genetic lines. Poult. Sci. 98:5465-5476.

Havenstein, G. B., P. R. Ferket, and M. A. Qureshi. 2003a. Growth, livability, and feed conversion of 1957 vs 1991 broilers when fed "typical" 1957 and 1991 broiler diets. Poult. Sci. 82:1500-1508.

Havenstein, G. B., P. R. Ferket, and M. A. Qureshi. 2003b. Carcass composition and yield of 1957 versus 2001 broilers when fed representative 1957 and 2001 broiler diets. Poult. Sci. 82:1509-1518.

Havenstein, G. B., P. R. Ferket, S. E. Scheideler, and B. T. Larson. 1994. Growth, livability, and feed conversion of 1957 vs 1991 broilers when fed "typical" 1957 and 1991 broiler diets. Poult. Sci. 73:1785-1794.

Hosotani, M., T. Kawasaki, Y. Hasegawa, Y. Wakasa, M. Hoshino, N. Takahashi, H. Ueda, T. Takaya, T. Iwasaki, and T. Watanabe. 2020. Physiological and pathological mitochondrial clearance is related to Pectoralis major muscle pathogenesis in broilers with wooden breast syndrome. Front Physiol. 11:579.

Hoving-Bolink, A. H., R. W. Kranen, R. E. Klont, C. L. M. Gerritsen, and K. H. De Greef. 2000. Fibre area and capillary supply in broiler breast muscle in relation to productivity and ascites. Meat Sci. $56: 397-402$

Hussein, E. O. S., G. M. Suliman, A. N. Al-Owaimer, S. H. Ahmed, A. M. Abudabos, M. E. Abd El-Hack, A. E. Taha, I. M. Saadeldin, and A. A. Swelum. 2019. Effects of stock, sex, and muscle type on carcass characteristics and meat quality attributes of parent broiler breeders and broiler chickens. Poult. Sci. 98:6586-6592.

Kawasaki, T., T. Yoshida, and T. Watanabe. 2016. Simple method for screening the affected birds with remarkably hardened Pectoralis major muscles among broiler chickens. J. Poult. Sci. 53:291-297.

Knowles, T. G., S. C. Kestin, S. M. Haslam, S. N. Brown, L. E. Green, A. Butterworth, S. J. Pope, D. Pfeiffer, and C. J. Nicol. 2008. Leg 
disorders in broiler chickens: Prevalence, risk factors and prevention. PLoS One 3:1-5.

Kuttappan, V. A., V. B. Brewer, J. K. Apple, P. W. Waldroup, and C. M. Owens. 2012a. Influence of growth rate on the occurrence of white striping in broiler breast fillets. Poult. Sci. 91:2677-2685.

Kuttappan, V. A., V. B. Brewer, F. D. Clark, S. R. McKee, J. F. Meullenet, J. L. Emmert, and C. M. Owens. 2009. Effect of white striping on the histological and meat quality characteristics of broiler fillets. Poult. Sci. 88:136-137 (Abstr.).

Kuttappan, V. A., V. B. Brewer, A. Mauromoustakos, S. R. McKee, J. L. Emmert, J. F. Meullenet, and C. M. Owens. 2013a. Estimation of factors associated with the occurrence of white striping in broiler breast fillets. Poult. Sci. 92:811-819.

Kuttappan, V. A., S. D. Goodgame, C. D. Bradley, A. Mauromoustakos, B. M. Hargis, P. W. Waldroup, and C. M. Owens. 2012b. Effect of different levels of dietary vitamin E (DL- $\alpha$-tocopherol acetate) on the occurrence of various degrees of white striping on broiler breast fillets. Poult. Sci. 91:3230-3235.

Kuttappan, V. A., B. M. Hargis, and C. M. Owens. 2016. White striping and woody breast myopathies in the modern poultry industry: A review. Poult. Sci. 95:2724-2733.

Kuttappan, V. A., G. R. Huff, W. E. Huff, B. M. Hargis, J. K. Apple, C. Coon, and C. M. Owens. 2013b. Comparison of hematologic and serologic profiles of broiler birds with normal and severe degrees of white striping in breast fillets. Poult. Sci. 92:339-345

Kuttappan, V. A., Y. S. Lee, G. F. Erf, J. F. C. Meullenet, S. R. Mckee, and C. M. Owens. 2012c. Consumer acceptance of visual appearance of broiler breast meat with varying degrees of white striping. Poult. Sci. 91:1240-1247.

Kuttappan, V. A., C. M. Owens, C. Coon, B. M. Hargis, and M. Vazquez-A Non. 2017. Research Note Incidence of broiler breast myopathies at 2 different ages and its impact on selected raw meat quality parameters. Poult. Sci. 96:3005-3009.

Kuttappan, V. A., H.l. Shivaprasad, D. P. Shaw, B. A. Valentine, B. M. Hargis, F. D. Clark, S. R. McKee, and C. M. Owens. 2013c. Pathological changes associated with white striping in broiler breast muscles. Poult. Sci. 92:331-338.

Lake, J. A., and B. Abasht. 2020. Glucolipotoxicity: a proposed etiology for wooden breast and related myopathies in commercial broiler chickens. Front. Physiol. 11:169.

Lake, J. A., E. M. Brannick, M. B. Papah, C. Lousenberg, S. G. Velleman, and B. Abasht. 2020. Blood gas disturbances and disproportionate body weight distribution in broilers with wooden breast. Front. Physiol. 11:304.

Lake, J. A., M. B. Papah, and B. Abasht. 2019. Increased expression of lipid metabolism genes in early stages of wooden breast links myopathy of broilers to metabolic syndrome in humans. Genes (Basel) 10:746.

Livingston, M. L., P. R. Ferket, J. Brake, and K. A. Livingston. 2019. Dietary amino acids under hypoxic conditions exacerbates muscle myopathies including wooden breast and white stripping. Poult. Sci. 98:1517-1527.

López, K. P., M. W. Schilling, and A. Corzo. 2011. Broiler genetic strain and sex effects on meat characteristics. Poult. Sci. 90:11051111.

Lorenzi, M., S. Mudalal, C. Cavani, and M. Petracci. 2014. Incidence of white striping under commercial conditions in medium and heavy broiler chickens in Italy. J. Appl. Poult. Res. 23:754-758.

MacRae, V. E., M. Mahon, S. Gilpin, D. A. Sandercock, and M. A. Mitchell. 2006. Skeletal muscle fibre growth and growth associated myopathy in the domestic chicken (Gallus domesticus). Br. Poult. Sci. 47:264-272.

Mehaffey, J. M., S. P. Pradhan, J. F. Meullenet, J. L. Emmert, S. R. McKee, and C. M. Owens. 2006. Meat quality evaluation of minimally aged broiler breast fillets from five commercial genetic strains. Poult. Sci. 85:902-908.

Mohammadigheisar, M., V. L. Shouldice, S. Torrey, T. Widowski, and E. G. Kiarie. 2020. Research Note: Comparative gastrointestinal, tibia, and plasma attributes in 48-day-old fast- and slow-growing broiler chicken strains. Poult. Sci. 99:3086-3091.

Mudalal, S., M. Lorenzi, F. Soglia, C. Cavani, and M. Petracci. 2015. Implications of white striping and wooden breast abnormalities on quality traits of raw and marinated chicken meat. Animal 9:728734 .
Norring, M., A. Valros, J. Valaja, H.-K. Sihvo, K. Immonen, and E. Puolanne. 2018. Wooden breast myopathy links with poorer gait in broiler chickens. Animal 13:1-6.

Nyuiadzi, D., C. Berri, L. Dusart, A. Travel, B. Méda, I. Bouvarel, L. A. Guilloteau, P. Chartrin, V. Coustham, C. Praud, E. Le Bihan-Duval, J. K. Tona, and A. Collin. 2020. Short cold exposures during incubation and postnatal cold temperature affect performance, breast meat quality, and welfare parameters in broiler chickens. Poult. Sci. 99:857-868.

Oviedo-Rondón, E. O., S. G. Velleman, and M. J. Wineland. 2020. The role of incubation conditions in the onset of avian myopathies. Front. Physiol. 11:1160.

Papah, M. B., E. M. Brannick, C. J. Schmidt, and B. Abasht. 2017. Evidence and role of phlebitis and lipid infiltration in the onset and pathogenesis of Wooden Breast Disease in modern broiler chickens. Avian Pathol. 46:623-643.

Petracci, M., G. Baldi, and F. Soglia. 2021. Spaghetti meat abnormality in broilers: current understanding and future research directions. Front. Physiol. 12:715.

Petracci, M., S. Mudalal, A. Bonfiglio, and C. Cavani. 2013. Occurrence of white striping under commercial conditions and its impact on breast meat quality in broiler chickens. Poult. Sci. 92:1670-1675.

Petracci, M., S. Mudalal, F. Soglia, and C. Cavani. 2015. Meat quality in fast-growing broiler chickens. Worlds. Poult. Sci. J. 71:363-374.

Petracci, M., F. Soglia, M. Madruga, L. Carvalho, E. Ida, and M. Estévez. 2019. Wooden-breast, white striping, and spaghetti meat: Causes, consequences and consumer perception of emerging broiler meat abnormalities. Compr. Rev. Food Sci. Food Saf. 18:565-583.

Sachs, N. J., A. R. Hampton, K. K. Foster, M. Y. Pechanec, J. D. Henderson, A. J. King, and M. J. Mienaltowski. 2019. The effects of an alternative diet regimen with natural methionine ingredients on white striping breast myopathy in broiler chickens. Poult. Sci. 98:413-421.

Santos, M. N., T. Widowski, E. Kiarie, M. Mohammadigheisar, I. Mandell, and S. Torrey. 2018. The impact of low-nutrient and conventional diets on lameness, tibial dimensions and tibial ash concentrations for two fast- growing genotypes of broiler chickens. Poul. Sci. 97(Suppl. 1):166 (Abstr.)

Shim, M. Y., M. Tahir, A. B. Karnuah, M. Miller, T. D. Pringle, S. E. Aggrey, and G. M. Pesti. 2012. Strain and sex effects on growth performance and carcass traits of contemporary commercial broiler crosses. Poult. Sci. 91:2942-2948.

Siegel, P. B., C. F. Honaker, and W. M. Rauw. 2009. Selection for High Production in Poultry. CABI Publishing, Wallingford, UK, $230-242$.

Sihvo, H. K., N. Airas, J. Lindén, and E. Puolanne. 2018. Pectoral vessel density and early ultrastructural changes in broiler chicken wooden breast myopathy. J. Comp. Pathol. 161:1-10.

Sihvo, H. K., K. Immonen, and E. Puolanne. 2014. Myodegeneration with fibrosis and regeneration in the Pectoralis major muscle of broilers. Vet. Pathol. 51:619-623.

da Silva-Buzanello, R. A., A. F. Schuch, A. W. Gasparin, A. S. Torquato, F. R. Scremin, C. Canan, and A. L. Soares. 2019. Quality parameters of chicken breast meat affected by carcass scalding conditions. Asian-Australas. J. Anim. Sci. 32:1186-1194.

Singh, M., A. J. Lim, W. I. Muir, and P. J. Groves. 2021. Comparison of performance and carcass composition of a novel slow-growing crossbred broiler with fast-growing broiler for chicken meat in Australia. Poult. Sci. 100:100966.

Sirri, F., C. Castellini, M. Bianchi, M. Petracci, A. Meluzzi, and A. Franchini. 2011. Effect of fast-, medium- and slow-growing strains on meat quality of chickens reared under the organic farming method. Animal 5:312-319.

Soglia, F., S. Mudalal, E. Babini, M. Di Nunzio, M. Mazzoni, F. Sirri, C. Cavani, and M. Petracci. 2016. Histology, composition, and quality traits of chicken Pectoralis major muscle affected by wooden breast abnormality. Poult. Sci. 95:651-659.

Torrey, S., M. Mohammadigheisar, M. Nascimento dos Santos, D. Rothschild, L. C. Dawson, Z. Liu, E. G. Kiarie, A. M. Edwards, I. Mandell, N. Karrow, D. Tulpan, and T. M. Widowski. 2021. In pursuit of a better broiler: growth, efficiency, and mortality of 16 strains of broiler chickens. Poult. Sci. 100:100955.

Trocino, A., A. Piccirillo, M. Birolo, G. Radaelli, D. Bertotto, E. Filiou, M. Petracci, and G. Xiccato. 2015. Effect of genotype, gender and feed restriction on growth, meat quality and the 
occurrence of white striping and wooden breast in broiler chickens. Poult. Sci. 94:2996-3004.

Velleman, S. G., and D. L. Clark. 2015. Histopathologic and myogenic gene expression changes associated with wooden breast in broiler breast muscles. Avian Dis. 59:410-418.

Wideman, R. F. 2016. Bacterial chondronecrosis with osteomyelitis and lameness in broilers: A review. Poult. Sci. 95:325-344.
Wilson, B. W., P. S. Nieberg, R. J. Buhr, B. J. Kelly, and F. T. Shultz. 1990. Turkey muscle growth and focal myopathy. Poult. Sci. 69:1553-1562.

Young, L. L., J. K. Northcutt, R. J. Buhr, C. E. Lyon, and G. O. Ware. 2001. Effects of age, sex, and duration of postmortem aging on percentage yield of parts from broiler chicken carcasses. Poult. Sci. 80:376-379. 